\title{
Near infrared nadir retrieval of vertical column densities: methodology and application to SCIAMACHY
}

\author{
S. Gimeno García ${ }^{1,2}$, F. Schreier ${ }^{1}$, G. Lichtenberg ${ }^{1}$, and S. Slijkhuis ${ }^{1}$ \\ ${ }^{1}$ DLR - German Aerospace Center, Remote Sensing Technology Institute, Oberpfaffenhofen, 82234 Weßling, Germany \\ ${ }^{2}$ TUM - Technical University of Munich, 80333 München, Germany
}

Received: 6 May 2011 - Published in Atmos. Meas. Tech. Discuss.: 10 June 2011

Revised: 7 October 2011 - Accepted: 20 November 2011 - Published: 8 December 2011

\begin{abstract}
Nadir observations with the shortwave infrared channels of SCIAMACHY on-board the ENVISAT satellite can be used to derive information on atmospheric gases such as $\mathrm{CO}, \mathrm{CH}_{4}, \mathrm{~N}_{2} \mathrm{O}, \mathrm{CO}_{2}$, and $\mathrm{H}_{2} \mathrm{O}$. For the operational level $1 \mathrm{~b}-2$ processing of SCIAMACHY data, a new retrieval code BIRRA (Beer InfraRed Retrieval Algorithm) has been developed. BIRRA performs a nonlinear or separable least squares fit (with bound constraints optional) of the measured radiance, where molecular concentration vertical profiles are scaled to fit the observed data. Here we present the forward modeling (radiative transfer) and inversion (least squares optimization) fundamentals of the code along with the further processing steps required to generate higher level products such as global distributions and time series. Moreover, various aspects of level 1 (observed spectra) and auxiliary input data relevant for successful retrievals are discussed. BIRRA is currently used for operational analysis of carbon monoxide vertical column densities from SCIAMACHY channel 8 observations, and is being prepared for methane retrievals using channel 6 spectra. A set of representative $\mathrm{CO}$ retrievals and first $\mathrm{CH}_{4}$ results are presented to demonstrate BIRRA's capabilities.
\end{abstract}

\section{Introduction}

Nadir sounding of molecular column densities is well established in atmospheric remote sensing. For UV instruments observing the back-scattered sunlight, the analysis is traditionally based on a DOAS (Differential Optical

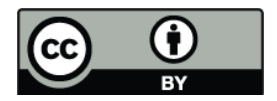

Correspondence to: S. Gimeno García (sebastian.gimenogarcia@dlr.de)
Absorption Spectroscopy) methodology that considers the logarithm of the measured signal - essentially the optical depth. This approach has also been successfully applied to SCIAMACHY's (Scanning Imaging Absorption Spectrometer for Atmospheric CHartographY) (Bovensmann et al., 1999; Gottwald and Bovensmann, 2011) near infrared (NIR) channels (Buchwitz et al., 2007; Frankenberg et al., 2005b). Alternatively, the measured radiance spectra can be directly analyzed. This method is common practice in thermal infrared atmospheric spectroscopy and constitutes the core of the Iterative Maximum Likelihood Method (IMLM) developed by SRON for analysis of SCIAMACHY's near infrared channels (Gloudemans et al., 2005). Recently, Reuter et al. (2010) also presented an optimum estimation analysis of sun normalized radiances for improved SCIAMACHY $\mathrm{CO}_{2}$ retrievals and Lerot et al. (2010) applied a direct fitting to nadir viewing UV spectra.

The aim of SCIAMACHY nadir NIR observations is to retrieve information on atmospheric gases such as $\mathrm{CO}, \mathrm{CH}_{4}$, $\mathrm{CO}_{2}, \mathrm{~N}_{2} \mathrm{O}$, or $\mathrm{H}_{2} \mathrm{O}$. Ideally, profiles of volume mixing ratio $q_{\mathrm{X}}(z)$ or number density $n_{\mathrm{X}}(z)=q_{\mathrm{X}}(z) \cdot n_{\mathrm{air}}(z)$ of a given molecule $X$ can be retrieved, where $z$ represents altitude and $n_{\text {air }}$ air number density. However, vertical sounding inversions are generally ill-posed problems, so for weakly absorbing gases it is customary to retrieve only vertical column densities (VCD),

$N_{\mathrm{X}} \equiv \int_{z_{\text {sff }}}^{z \mathrm{TOA}} n_{\mathrm{X}}(z) \mathrm{d} z$

where $z_{\text {srf }}$ is the surface altitude and $z_{\text {TOA }}$ the altitude of top of the atmosphere (TOA).

In order to have a flexible and robust inversion algorithm for the efficient processing of level- $1 b$ to level- 2 data, the "Beer InfraRed Retrieval Algorithm" (BIRRA) has been developed at DLR. BIRRA performs a nonlinear least squares

Published by Copernicus Publications on behalf of the European Geosciences Union. 
fit of the observed near infrared (sun-normalized) radiances. First results including a careful intercomparison with the WFM-DOAS algorithm (Weighting Function Modified DOAS, University of Bremen, Buchwitz et al., 2007) for orbit 8663 (27 October 2003) have been presented in Schreier et al. (2007). Recently, the BIRRA prototype has been successfully implemented in version 5 of the level $1 \mathrm{~b}$ to 2 SCIAMACHY processor for operational data retrievals.

In this paper, the algorithmic basis of BIRRA and its application to carbon gas VCD retrievals are presented. The next section reviews the forward model and the inversion approach used in BIRRA as well as further processing steps. Aspects of input data (nb. level 1 issues) and retrieval settings are discussed in Sect. 3. Section 4 contains a survey of VCD retrieval results. Conclusions and an outlook are given in Sect. 5. The results presented here have been obtained with the scientific prototype version of BIRRA and may differ from the SCIAMACHY operational product. The emphasis of this paper is on methodology, where carbon monoxide and methane retrievals are presented for illustrations. For a discussion of spatial and temporal patterns we refer to, e.g. Buchwitz et al., 2007; Clerbaux et al., 2008; Gloudemans et al., 2006, 2009; de Laat et al., 2006, 2007; Worden et al., 2010; Yurganov et al., 2008. A comprehensive discussion of results for $\mathrm{CO}$ and $\mathrm{CH}_{4}$, including validation, will be the subject of a forthcoming paper.

\section{Theory and algorithm}

\subsection{The forward model - near infrared radiative transfer}

For an arbitrary slant path, the intensity (radiance) $I$ at wavenumber $v$ received by an instrument at $s=0$ is described by the equation of radiative transfer (Liou, 1980; Zdunkowski et al., 2007)

$I(v)=I_{\mathrm{b}}(v) \mathcal{T}(v)-\int_{0}^{\infty} \mathrm{d} s^{\prime} J\left(v, s^{\prime}\right) \frac{\partial \mathcal{T}\left(v ; s^{\prime}\right)}{\partial s^{\prime}}$,

where $I_{\mathrm{b}}$ is an external contribution, $\mathcal{T}$ represents the transmission through the atmosphere, and $J$ is the source function comprised of thermal emission and scattering. In the near infrared, thermal emission of the atmosphere and Earth's surface is negligible compared to the reflected and scattered sunlight. The contribution of molecular (Rayleigh) scattering is far below $1 \%$ and will be neglected. Aerosol and cloud scattering may have a significant contribution to the intensity but their effects on the retrieval can be mitigated by proxy modeling (see Subsect. 2.3.1, a detailed justification can be found in Frankenberg et al., 2006; Gloudemans et al., 2008). Thus, neglecting scattering, Eq. (2) reduces to Beer's law for a double path through the atmosphere

$I(v)=\frac{r(v)}{\pi} \mu_{\odot} I_{\text {sun }}(v) \mathcal{T}_{\uparrow}(v) \mathcal{T}_{\downarrow}(v)$

$$
\begin{aligned}
& =\frac{r(v)}{\pi} \mu_{\odot} I_{\text {sun }}(v) \\
& \exp \left[-\int_{\text {earth }}^{\text {sun }} \mathrm{d} s^{\prime} \sum_{m} n_{m}\left(s^{\prime}\right) k_{m}\left(v, p\left(s^{\prime}\right), T\left(s^{\prime}\right)\right)\right] . \\
& \exp \left[-\int_{\text {earth }}^{\text {sat }} \mathrm{d} s^{\prime \prime} \sum_{m} n_{m}\left(s^{\prime \prime}\right) k_{m}\left(v, p\left(s^{\prime \prime}\right), T\left(s^{\prime \prime}\right)\right)\right],
\end{aligned}
$$

where $r$ is the surface albedo and $\mathcal{T}_{\uparrow}$ and $\mathcal{T}_{\downarrow}$ (with $\mathcal{T}=\mathcal{T}_{\uparrow} \mathcal{T}_{\downarrow}$ ) denote transmission between reflection point (e.g. Earth surface at altitude $z_{\text {srf }}$ ) and observer and between Sun and reflection point, respectively.

Assuming spherical symmetry, the path variable $s$ is uniquely related to the altitude $z$ (in a plane-parallel approximation $s^{\prime}=z^{\prime} / \mu$ with $\mu \equiv \cos \theta$ for an observer zenith angle $\theta$, similarly $s^{\prime \prime}=z^{\prime \prime} / \mu_{\odot}$ for a solar zenith angle (SZA) $\theta_{\odot}$ ). $k_{m}$ and $n_{m}$ are the (pressure $p$ and temperature $T$ dependent) absorption cross section and number density of molecule $m$. In infrared line-by-line models, the absorption cross section $k_{m}$ of molecule $m$ is obtained by summing up the contributions from many lines,

$k_{m}(\nu, p, T)=\sum_{l} S_{l}^{(m)}(T) g\left(v ; \hat{v}_{l}^{(m)}, \gamma_{l}^{(m)}(p, T)\right)$,

where each individual line $l$ is described by the product of the temperature-dependent line strength $S_{l}^{(m)}$ and a normalized line shape function $g$ describing the broadening mechanism. $\hat{v}$ and $\gamma$ are line position and half width at half maximum (HWHM), respectively. The combined effect of pressure broadening (corresponding to a Lorentzian line shape) and Doppler broadening (Gaussian line shape) is represented by a Voigt line profile (Schreier, 2011). Line mixing (LM) is not yet considered in BIRRA. Tran et al. (2010) discussed consequences of line mixing in the $2 v_{3}$ band of methane for molecular spectroscopy and atmospheric retrievals, concluding that "from the point of view of atmospheric retrievals, neglecting LM with suitable effective line parameters is convenient and accurate (within current retrieval uncertainties)."

The measured spectrum is modeled by convolution of the monochromatic intensity spectrum (3) with a normalized instrument spectral response function $\mathcal{S}$

$\widehat{I}(v) \equiv(I \otimes \mathcal{S})(v)=\int_{-\infty}^{\infty} I\left(v^{\prime}\right) \times \mathcal{S}\left(v-v^{\prime}\right) \mathrm{d} v^{\prime}$,

For SCIAMACHY measurements, a Gaussian function is commonly used,

$\mathcal{S}_{\mathrm{G}}(\nu, \gamma)=\frac{1}{\gamma}\left(\frac{\ln 2}{\pi}\right)^{1 / 2} \cdot \exp \left[-\ln 2\left(\frac{\nu}{\gamma}\right)^{2}\right]$,

where $\gamma$ is the half width at half maximum (HWHM). The BIRRA forward model is based on GARLIC (Generic Atmospheric Radiation Line-by-line Infrared Code), the Fortran 90/2003 reimplementation of the Fortran 77 code MIRART (Schreier and Schimpf, 2001). GARLIC/MIRART is 
a line-by-line code for arbitrary observation constellations (up-looking, down-looking or limb-viewing in a spherical geometry), and instrumental field-of-view and spectral response. GARLIC/MIRART has been verified in extensive intercomparisons (e.g. von Clarmann et al., 2002; Melsheimer et al., 2005); recently, Hedelt et al. (2011) used the code successfully to model observations of the Venus transit 2004 made by the Tenerife Vacuum Tower Telescope. Furthermore, a multiple scattering enhanced version of MIRART has been used to study effects of cirrus clouds on mid infrared limb MIPAS observations (Mendrok et al., 2007). Molecular spectroscopic parameters from HITRAN, GEISA, or JPL databases can be selected; additionally continuum corrections to the molecular absorption are considered, e.g. the CKD continuum of water (Clough et al., 1989). Jacobians, i.e. derivatives of transmission or radiance spectra with respect to the parameters to be retrieved, are obtained by means of automatic differentiation (Griewank, 2000; Hascoët and Pascual, 2004). For nadir modeling, refraction is only taken into account for the Sun - Earth path element whereas for the "down-looking" path segment (satellite - Earth's surface) with viewing angles $\leq 30^{\circ}$ refraction is neglected.

\subsection{The inverse problem - least squares}

Denoting by $\alpha_{m}$ the molecular scale factor to be estimated and by $n_{m}^{\text {prior }}(z)$ the a-priori (e.g. climatological) number density of molecule $m$, the total path transmission in Eq. (3) can be written as

$\mathcal{T} \equiv \mathcal{T}_{\uparrow} \mathcal{T}_{\downarrow}=\exp \left[-\sum_{m} \tau_{m}\right]=\exp \left[-\sum_{m} \alpha_{m} \tau_{m}^{\text {prior }}\right]$,

where $\tau_{m}$ is the "true" total optical depth of molecule $m$ (note that for simplicity this equation is written for a non-refractive plane-parallel geometry),

$\tau_{m}(v)=\int_{z_{\text {sff }}}^{z_{\mathrm{TOA}}} \mathrm{d} z^{\prime}\left(\frac{1}{\mu}+\frac{1}{\left|\mu_{\odot}\right|}\right) n_{m}\left(z^{\prime}\right) k_{m}\left(v, z^{\prime}\right)$,

and $\tau_{m}^{\text {prior }}$ the a-priori total optical depth computed with $n^{\text {prior }}$ (Note that for simplicity this equation is written for a planeparallel non-refractive atmosphere). From Eq. (6), we have that $\tau_{m}(v)=\alpha_{m} \tau_{m}^{\text {prior }}$.

If the observation geometry (i.e. $z_{\text {srf }}, z_{\mathrm{TOA}}, \mu$ and $\mu_{\odot}$ ) is known, changes in the a-priori molecular cross sections $k_{m}$ are neglected and it is assumed that the scale factors do not depend on altitude, then, recalling Eq. (1), the "true" VCD of the molecule $m$ can be written as

$N_{m}=\alpha_{m} N_{m}^{\text {prior }}$,

where $N_{m}^{\text {prior }}=\int_{z_{\text {sff }}}^{z_{\mathrm{TOA}}} n_{m}^{\text {prior }}(z) \mathrm{d} z$ is the a-priori VCD of the molecule $m$.

In addition to the scaling factors $\alpha_{m}$, the surface albedo $r$ (generally modeled by a polynomial in wavenumber) is treated as an unknown; furthermore, instrumental parameters (i.e. the slit function half width) and an optional baseline correction $b$ (again a polynomial) can be considered as fit parameters.

\subsubsection{Nonlinear least squares}

The standard approach to estimate unknown quantities $\boldsymbol{x} \in$ $\mathbb{R}^{n}$ from measurements $\boldsymbol{y} \in \mathbb{R}^{m}$ relies on a (generally nonlinear) least squares fit

$\min _{x}\|\boldsymbol{y}-\boldsymbol{F}(\boldsymbol{x})\|^{2}$.

Here, $\boldsymbol{F}$ denotes the forward model $F: \mathbb{R}^{n} \rightarrow \mathbb{R}^{m}$ essentially given by the radiative transfer and instrument model,

$$
\begin{aligned}
\boldsymbol{F}(\boldsymbol{x}) & \equiv \widehat{I}(v)=\frac{r(v)}{\pi} \mu_{\odot} I_{\text {sun }}(v) \\
& \times \exp \left[-\sum_{m} \alpha_{m} \tau_{m}(v)\right] \otimes \mathcal{S}(v, \gamma)+b(v),
\end{aligned}
$$

where the state vector $\boldsymbol{x} \equiv(\boldsymbol{\alpha}, \gamma, \boldsymbol{r}, \boldsymbol{b})$ is comprised of molecular scale parameters $\alpha$, and optionally "auxiliary" parameters $\gamma, \boldsymbol{r}, \boldsymbol{b}$ (the arrays $\boldsymbol{r}$ and $\boldsymbol{b}$ denote the coefficients of the polynomials in wavenumber).

For the solution of the nonlinear least squares problem, Eq. (9), BIRRA uses solvers provided in the PORT Optimization Library (Dennis, Jr. et al., 1981, available at http://www.netlib.org/port/) based on a scaled trust region strategy. Furthermore, BIRRA provides the option to use a nonlinear least squares with simple bounds to avoid unphysical results, e.g. non-negativity,

$\min _{x>0}\|\boldsymbol{y}-\boldsymbol{F}(\boldsymbol{x})\|^{2}$.

\subsubsection{Separable least squares}

Note that the surface albedo $r$ and the baseline correction(s) $b$ enter the forward model $\boldsymbol{F}$, Eq. (10), linearly and the least squares problems, Eqs. (9) and (11), can be reduced to a separable nonlinear least squares problem (Golub and Pereyra, 2003). Splitting the vector $\boldsymbol{x}$ of parameters to be fitted into a vector $\boldsymbol{\eta}$ of nonlinear parameters and a vector $\boldsymbol{\beta}$ of linear parameters, i.e.

$\boldsymbol{x} \longrightarrow(\boldsymbol{\eta}, \boldsymbol{\beta})$, with $\boldsymbol{x} \in \mathbb{R}^{n}$,

$\boldsymbol{\eta} \equiv(\boldsymbol{\alpha}, \boldsymbol{\gamma}) \in \mathbb{R}^{p}, \boldsymbol{\beta} \equiv(\boldsymbol{r}, \boldsymbol{b}) \in \mathbb{R}^{q}$ and $n=p+q$,

the forward model can be written as

$\boldsymbol{F}(\boldsymbol{x})=\sum_{l=1}^{q} \beta_{l} \boldsymbol{f}_{l}(\boldsymbol{\eta})$,

where $\boldsymbol{f}_{l}: \mathbb{R}^{p} \rightarrow \mathbb{R}^{m}$ for $l=1, \ldots, q$. Combining these functions in a matrix

$\mathrm{A}(\eta) \equiv\left(\boldsymbol{f}_{1}(\boldsymbol{\eta}), \boldsymbol{f}_{2}(\boldsymbol{\eta}), \ldots, \boldsymbol{f}_{q}(\boldsymbol{\eta})\right)$, with $\mathrm{A} \in \mathbb{R}^{m \times q}$, 
Equation (9) can be rewritten as a linear least squares problem

$$
\min _{\beta}\|\boldsymbol{y}-\mathrm{A} \boldsymbol{\beta}\|^{2}
$$

for the vector $\boldsymbol{\beta}$, that is formally solved by

$$
\boldsymbol{\beta}=\left(\mathrm{A}^{\mathrm{T}} \mathrm{A}\right)^{-1} \mathrm{~A}^{\mathrm{T}} \boldsymbol{y}
$$

Inserting this solution in Eq. (13), the original least squares problem Eq. (9) becomes

$$
\min _{\eta}\left\|\boldsymbol{y}-\sum_{l}\left(\left(\mathrm{~A}^{\mathrm{T}} \mathrm{A}\right)^{-1} \mathrm{~A}^{\mathrm{T}} \boldsymbol{y}\right)_{l} \boldsymbol{f}_{l}(\boldsymbol{\eta})\right\|^{2} .
$$

This is a nonlinear least squares problem for $\boldsymbol{\eta}$ independent of $\boldsymbol{\beta}$ and can be solved in the usual way by means of GaussNewton or Levenberg-Marquardt algorithms. Once the optimum $\boldsymbol{\eta}$ is found, the linear parameter vector $\boldsymbol{\beta}$ is obtained from Eq. (16). The main advantages of this approach are: (i) the nonlinear least squares solver has to iterate only over a reduced fit vector $\eta$; (ii) no initial guess is required for the linear parameters $\boldsymbol{\beta}$; (iii) the size of the Jacobian matrix is reduced.

\subsubsection{Jacobians and altitude sensitivity}

The Jacobian, $J \equiv \partial \boldsymbol{F} / \partial \boldsymbol{x}$, the partial derivatives of the model function with respect to the fit parameters, is an essential quantity required for Gauss-Newton type iterative solvers of nonlinear least squares problems. Although BIRRA performs a least squares fit of vertical column densities, derivatives with respect to the (discretized) molecular abundance profiles deliver insight into the sensitivity of the retrievals to different altitude regions in addition to useful hints to the appropriate spectral region selection.

According to Fig. 1, in SCIAMACHY channel 8 both branches of the first $\mathrm{CO}$ overtone band at $2.4 \mu \mathrm{m}$ have about the same impact, however, water interference is less significant in the R-branch between 4250 and $4300 \mathrm{~cm}^{-1}$. Furthermore, the plot indicates that the highest altitude sensitivity is located in the troposphere.

For an assessment of altitude sensitivity in the context of profile retrievals, specification of averaging kernels relating the true and estimated state vector (comprising the discretized profile) is customary. In case of column density retrievals as performed by BIRRA, the state vector is composed of the profile scaling factors $\alpha_{m}$ of all relevant molecules (and some additional auxiliary parameters). In order to estimate the altitude sensitivity, an approach suggested by Buchwitz et al. (2004) has been used, i.e. a series of BIRRA fits has been performed using synthetic spectra generated with perturbed CO profiles. Denoting $N^{\mathrm{r}}(z)$ the VCD retrieved from the spectrum generated with a profile perturbed at an altitude
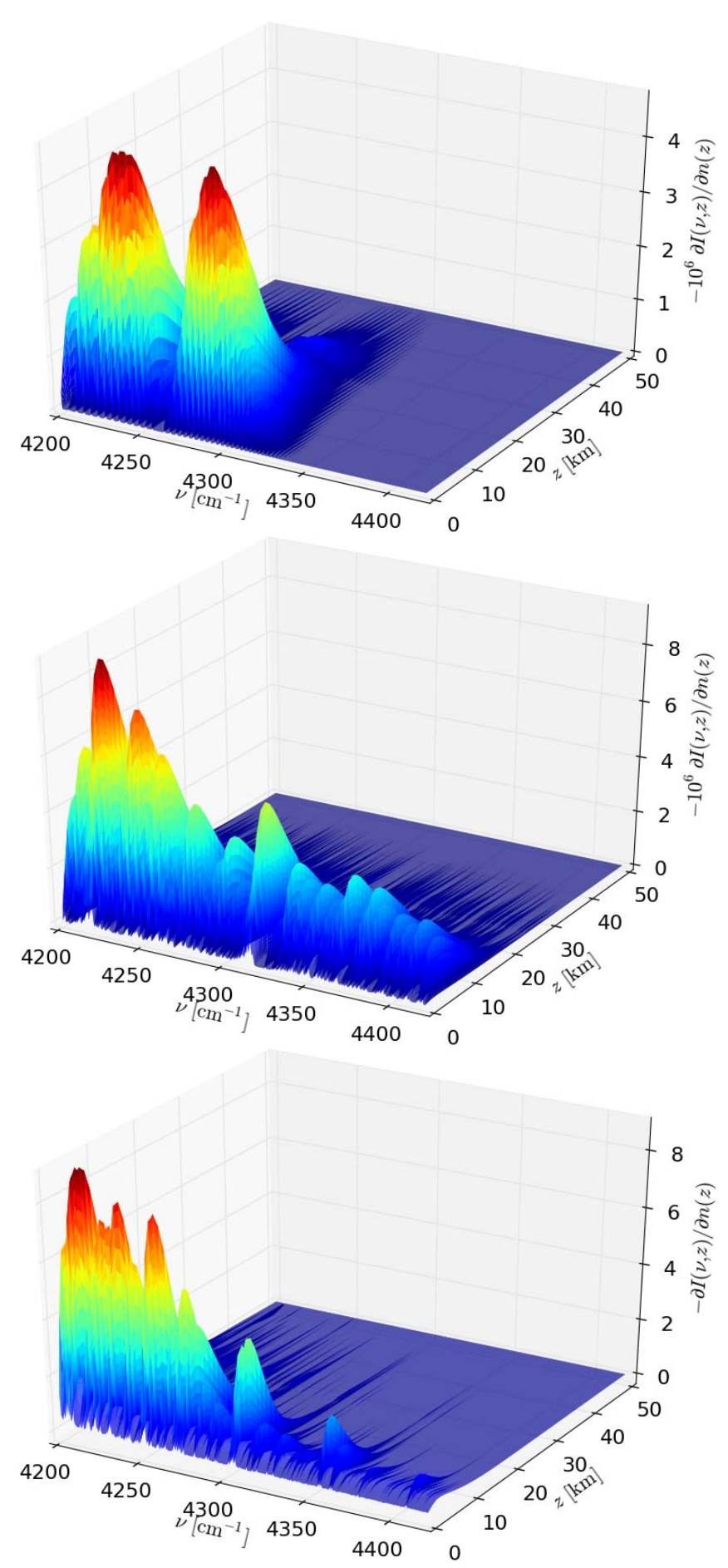

Fig. 1. Jacobians $\left[\mathrm{erg} / \mathrm{s} /\left(\mathrm{cm}^{2} \mathrm{srcm}^{-1}\right) / \mathrm{ppm}\right.$ ] for molecular concentration profile retrieval in channel 8: $\mathrm{CO}$ (top), $\mathrm{CH}_{4}$ (mid), and $\mathrm{H}_{2} \mathrm{O}$ (bottom). Note the scaling by $10^{6}$ of the $\mathrm{CO}$ and $\mathrm{CH}_{4} \mathrm{Jaco}^{-}$ bians. The derivatives were calculated using GARLIC for a US standard atmosphere up to $50 \mathrm{~km}$, a Gaussian slit function with $\gamma=0.2 \mathrm{~cm}^{-1}$, and vertical downlooking observer at $800 \mathrm{~km}$. 


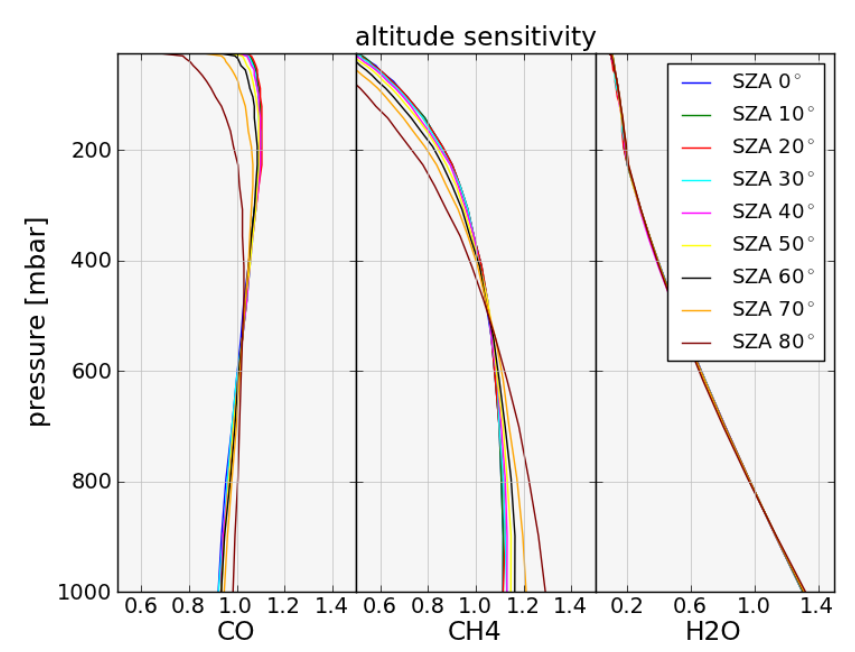

Fig. 2. Altitude sensitivity of $\mathrm{CO}$ (left), $\mathrm{CH}_{4}$ (mid), and $\mathrm{H}_{2} \mathrm{O}$ in channel 8.

$z$, and $N^{\mathrm{p}}(z) \mathrm{VCD}$ corresponding to this perturbed profile, the altitude sensitivity is estimated by

$A(z)=\frac{N^{\mathrm{r}}(z)-N}{N^{\mathrm{p}}(z)-N}$,

where $N$ is the true VCD as in Eq. (1) (the subscript $X$ is omitted for brevity). Fig. 2 confirms the high sensitivity of NIR retrievals in the lower troposphere; furthermore, as pointed out by Buchwitz et al. (2004) and Gloudemans et al. (2008), this sensitivity is depending on the solar zenith angle and, to lesser extent, on the observation angle.

\subsection{Postprocessing}

In the previous subsections, the basics of forward modeling (radiative transfer) and inversion (least squares optimization) as applied to a single observation have been presented. Here, we discuss further steps necessary to proceed from the fitted parameters during the inversion process to "higher level products" such as local and global spatial distributions and temporal evolutions.

\subsubsection{Product definition}

Since scattering is neglected in the BIRRA forward model, the photon path is considered to be the optical path that solar light travels from the top of the atmosphere to the Earth's surface, and reflected from the surface up to the observer. However, the measured radiance has a high probability of having also a (small or large, depending on the individual conditions) fraction coming from scattering events in the atmosphere, and consequently, having a photon path different from the pure geometrical one. In addition, the atmospheric conditions are set a-priori to climatological datasets but the actual meteorological conditions (e.g. pressure, temperature) at the time of the observations are unknown. Moreover, the quality of the observed spectra has a significant impact on the fitted scaling factors of the atmospheric constituents and, therefore, calibration open issues and the known growth of an ice layer on channel 8 detector (Gloudemans et al., 2005) will affect the retrievals.

In order to account for these unconsidered effects, the results of the retrieved gases are presented as "proxy"normalized vertical column densities instead of directly retrieved VCDs. As proxy, it is typical to select a fit parameter that contains information about the unaccounted issues. In case of CO retrievals from SCIAMACHY channel 8 , methane is a reasonably good candidate to be used as proxy (Buchwitz et al., 2000). $\mathrm{CH}_{4}$ has strong absorption lines across the $\mathrm{CO}$ spectral fitting window, so the amount of $\mathrm{CH}_{4}$ can be determined with high accuracy. Furthermore, $\mathrm{CH}_{4}$ is a well-mixed gas with long life time in the atmosphere and, consequently, it has quite homogeneous global distributions. The deviations of $\mathrm{CH}_{4}$ concentrations from the a-priori due to sources and sinks are rarely bigger than $10 \%$, far smaller than the deviations of $\mathrm{CO}$ that can easily depart by hundreds percent from the reference value over emitting areas. Thus, in terms of $\mathrm{CO}$ variability, $\mathrm{CH}_{4}$ can be considered as constant and variations in the retrieved $\mathrm{CH}_{4}$ from the expected a-priori value can be interpreted as the effect of the unconsidered processes. So, the proxy-normalized CO vertical column density is defined as

$\mathrm{xCO} \equiv N_{\mathrm{CO}}^{\text {prior }} \times \frac{\alpha_{\mathrm{CO}}}{\alpha_{\mathrm{CH} 4}}$,

where $N_{\mathrm{CO}}$ represents the a-priori $\mathrm{CO}$ vertical column density, and $\alpha_{\mathrm{CO}}$ and $\alpha_{\mathrm{CH} 4}$ are the fitted scaling factors of $\mathrm{CO}$ and $\mathrm{CH}_{4}$, respectively (see Eq. 8). Note that both scaling factors are retrieved from channel 8 data.

Considering that the retrieval of $\mathrm{CH}_{4}$ under the considerations of homogeneity exposed above is equivalent to the retrieval of the dry air mass, the ratioed quantity XCO is called dry-air column density (Wallace and Livingston, 1990; Yang et al., 2002). For channel 8 retrievals, however, the ice layer that grows over the detector has a different impact on $\mathrm{CH}_{4}$ than on $\mathrm{CO}$ retrievals. Thus, the $\mathrm{CH}_{4}$-proxy does not entirely account for the effect of the ice layer and special care has to be taken when correcting for this.

Analogously, using SCIAMACHY channel 6, one can define the dry-air column mixing ratio of $\mathrm{CH}_{4}$ as

$\mathrm{xCH} 4 \equiv q_{\mathrm{CH} 4}^{\text {prior }} \times \frac{\alpha_{\mathrm{CH} 4}}{\alpha_{\mathrm{CO} 2}}$,

where $q_{\mathrm{CH} 4}^{\text {prior }}$ is the a-priori column mixing ratio of $\mathrm{CH}_{4}$, and $\alpha_{\mathrm{CH} 4}$ and $\alpha_{\mathrm{CO} 2}$ are the scaling factors of $\mathrm{CH}_{4}$ and $\mathrm{CO}_{2}$, respectively. For the target species $\mathrm{CH}_{4}$, the chosen dry-air proxy is $\mathrm{CO}_{2}$ (Frankenberg et al., 2006). All conditions mentioned above for the $\mathrm{CH}_{4}$-proxy also hold for the proxy $\mathrm{CO}_{2}$. Further, $\mathrm{CO}_{2}$ is far more homogeneous (vertical and horizontally) than $\mathrm{CH}_{4}$, and the absorption signatures of target 
and proxy species are of comparable magnitude in channel 6 , which is desirable but not the case for the $\mathrm{CO}$ target with a $\mathrm{CH}_{4}$ proxy.

\subsubsection{Quality criteria}

In order to use the fitted data, a variety of quality criteria have to be fulfilled. Convergence of the least squares fit is requested and only moderate solar zenith angles (typically $<80 \mathrm{dg}$ ) are selected. Retrievals with high fit errors are rejected (typically $\left.\varepsilon\left(\alpha_{\mathrm{CO}}\right)<0.5, \varepsilon\left(\alpha_{\mathrm{CH} 4}\right)<0.01\right)$. Furthermore, for the acceptance or rejection of retrieved data a quantile analysis is performed, i.e. outliers far off the median are rejected. As suggested by Gloudemans et al. (2009), different cloud filters are used over land and over sea: in contrast to land observations, the NIR albedo of oceans is very low and, as a consequence, the signal-to-noise ratio of cloud free observations is very low. Thus, over oceans the presence of clouds with high albedo significantly enlarges the signal and enables reliable retrievals. Accordingly, only pixels with cloud fraction higher than $20 \%$ are accepted. Over land, however, the presence of clouds is a source of uncertainties, since the radiative transfer model only accounts for one photon path and, in case of partial cloud cover, the observed radiances have contributions coming from reflections at the Earth's surface and from scattering at the cloud layer. Therefore, only observations with cloud fraction below $20 \%$ are accepted.

Observations over ocean require special care. Cloud top height $(\mathrm{CTH})$ is a crucial parameter for trace gas retrieval under cloudy conditions. This is specially true for retrievals over the ocean, since clouds are unavoidable for reliable retrievals. In these cases, the main contribution to the measured intensity comes from the cloud top region, so this information helps to understand and improve the retrievals. Since $\mathrm{CH}_{4}$ is a well-mixed gas, variations in $\mathrm{CH}_{4} \mathrm{VCDs}$ can be related to "obstacles" along the photon path, mainly due to cloud shielding. Bounds on the $\mathrm{CH}_{4} \mathrm{VCD}$ are highly correlated with restrictions on cloud top height. This fact is exploited by Buchwitz et al. (2004, 2007). Gloudemans et al. (2009) used cloud information based on $\mathrm{CH}_{4}$ retrieved from SCIAMACHY channel-8 for ocean CO retrievals.

High clouds introduce uncertainties and systematic errors to the $\mathrm{CO}$ retrievals especially by the scaling with an incorrectly retrieved $\mathrm{CH}_{4}$ partial column. However, since retrievals in presence of high clouds translate, in most cases, to large $\mathrm{CH}_{4}$ retrieval errors, these can be used for masking out high cloud observations. Indeed, comparisons of xCO using the quality criteria previously described and using an extra condition on cloud top height (namely, CTH $<2 \mathrm{~km}$ ) show similar results, since most of the high cloud observations are already removed by the condition $\varepsilon\left(\alpha_{\mathrm{CH} 4}\right)<0.01$.

For $\mathrm{CO}$ retrievals, the normalization by the $\mathrm{CH}_{4}$ scaling factor accounts for deviations from geometrical photon paths. However, two systematic errors arise from this treatment. On the one hand, the ratio of the partial $\mathrm{CO}$ and $\mathrm{CH}_{4} \mathrm{VCDs}$ depends on the bottom boundary (surface or cloud top). Correcting for this, $\mathrm{xCO}$ retrieved only over clouds can be transferred to total vertical column densities, assuming that the retrieved-to-reference $\mathrm{VCD}$ ratio above and below the clouds is the same. On the other hand, $\mathrm{CO}$ and $\mathrm{CH}_{4}$ have different altitude sensitivity, so deviations from the reference profiles at different altitudes will have a different impact on the retrieved $\mathrm{CO}$ and $\mathrm{CH}_{4}$. This effect has not been considered. Nonetheless, below $500 \mathrm{mb}$ the altitude sensitivity of both gases is similar and hence, the error introduced is far smaller than the other contributions (given that high-cloud observations have been filtered out).

\section{Retrieval setup and input data: sensitivity studies}

The quality of the input data greatly affects the accuracy of the retrievals. Since model parameters are optimally varied during the inversion process to mimic the measured values, errors in the input spectra will lead to wrong retrievals. In this section, sensitivity studies with respect to input data and retrieval settings are presented for carbon monoxide.

Level 1 data (spectra and geolocation) are taken from the SCIAMACHY level 1 product (SGP version 6.03). Unless otherwise noted, the dead and bad pixel mask (DBPM) used corresponds to the prototype of the new level 1 SGP version 7.03. For topographic information (surface elevation) (ETOPO4) data are used. Auxiliary data such as cloud information are taken from the SCIAMACHY level 2 product SGP version 3.01.

\subsection{Level 1 spectra - trace gases fitting windows}

SCIAMACHY spectra are spectrally and radiometrically calibrated and corrected for several effects, namely: leakage current, pixel-to-pixel gain, non-linear response, stray light, and polarization. Reflectances are calculated using in-flight sun diffuser spectra. Additionally, the degradation of the instrument is monitored and the quality of the individual spectral pixels is assessed. For the $\mathrm{CO}$ retrievals presented here, the spectral window in the middle of channel 8, ranging $4282-4303 \mathrm{~cm}^{-1}$ (equivalent to $2323-2336 \mathrm{~nm}$ ) is used. For methane retrievals, two microwindows in channel 6 are selected: the $5986-6139 \mathrm{~cm}^{-1}(1629-1671 \mathrm{~nm})$ interval with $\mathrm{CH}_{4}$ as the strongest absorber, and the $6273-6419 \mathrm{~cm}^{-1}$ $(1558-1594 \mathrm{~nm})$ interval with $\mathrm{CO}_{2}$ as the strongest absorber.

\subsection{Dead \& bad pixel mask (DBPM)}

The DBPM contains pixels that are deemed unusable for the retrieval due to damage mostly caused by enhanced particle flux during the passing of the Southern Atlantic Anomaly (SAA). Consequences of the damage are, e.g. high noise values, disconnection or very high leakage currents. Dark, sun, and internal lamp measurements are used to determine bad 

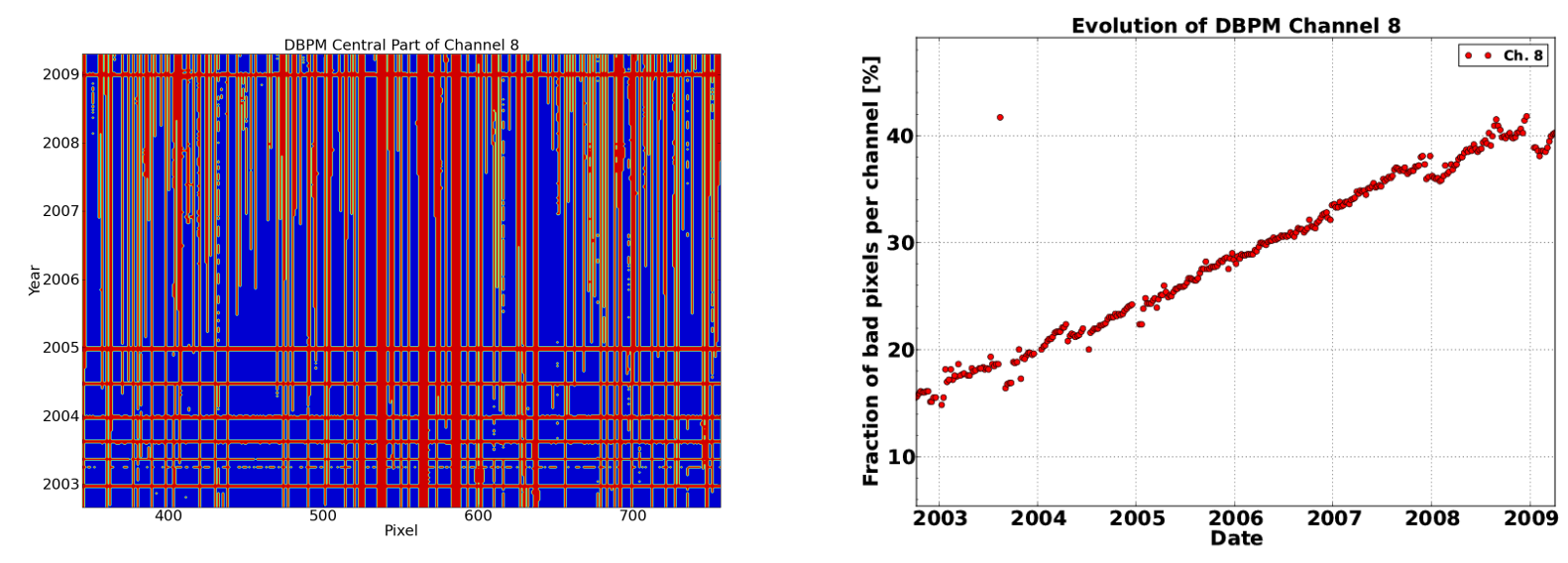

Fig. 3. Evolution of pixel mask from 2002 to 2009 (left) and percentage of flagged pixels (right). Good pixels are marked blue and bad pixels red. Several decontaminations rendering the detectors temporarily useless due to high temperatures and resulting noise are visible as horizontal red lines in the left diagram.

pixels (see, e.g. Lichtenberg et al., 2006), and parameters such as mean noise or error of dark parameters are calculated. The DBPM judges the quality of a pixel by setting channel wide thresholds for dark signal, dark signal noise, dark signal saturation, residual of dark correction, and sun and white light source signal. If one or more thresholds is/are violated in more than $40 \%$ of the cases within one week, the pixel is masked as bad. The algorithm is based on an approach described by SRON (personal communication, October 2006). Furthermore, a pixel is always either bad or good, there are no intermediate values.

Since mission start, the number of dead/bad pixels has grown steadily, cf. Fig. 3a, and in June 2009 around $40 \%$ of the pixels in channel 8 are marked as bad. Fig. 4 shows the effect on CO VCD retrievals of using a constant mask for one year vs. using a dynamic mask continuously updated Lichtenberg et al. (2010). Even though the total number of flagged pixels does not change dramatically between February and October 2004, cf. Fig. 3b, the retrieved VCDs differ significantly, i.e. CO fits depend on the presence of the individual pixels and their quality. This result was already found earlier by Gloudemans et al. (2005) for CO retrievals with the IMLM algorithm.

\subsection{Sensitivity to signal changes in individual pixels}

An inversion process aims at gaining information about model parameters from observed quantities. In the case of atmospheric gas retrievals, the observed quantities are the radiances measured at different wavelengths for a light beam that has traveled through the Earth's atmosphere. Since the absorption of light by atmospheric gas constituents is wavelength-dependent, the discrete measured radiance spectrum contains implicit information of gas concentrations: the higher the concentration of molecule $m$, the lower the radiance at wavelengths where gas $m$ absorbs (see Sect. 2.1 for details).
In this subsection, the spectral sensitivity of the molecular scaling factors $\alpha_{m}$ is studied by sequential perturbations on individual pixels of SCIAMACHY channel 8 . On the one hand, a response of a molecular scaling factor $\alpha_{m}$ to a perturbation on a given spectral pixel means that this pixel contains information about the atmospheric content of molecule $m$ and that the inclusion of this pixel would be beneficial for the inversion. On the other hand, some radiative and spectroscopic aspects such as the interference of spectral lines of the target gas with strong lines of other gases, or insufficient knowledge of molecular absorption cross sections due to imprecise spectral line parameters can lead to errors during the inversion process. Consequently, those critical pixels where perturbations have large impacts on several molecules at the same time should be treated with care.

A synthetic SCIAMACHY spectrum covering the whole channel (1004 pixels ignoring the blinded 20 pixels at the left and right ends) with a representative viewing geometry was produced by means of GARLIC (the BIRRA forward model). An inversion of this unperturbed noise-free "reference" spectrum delivers scaling factors of unity for all gases. Gradually, the intensity spectrum was perturbed pixel by pixel by constant amounts:

$$
\begin{aligned}
& I_{i j}^{\text {pert }}=\left(1+a_{j}\right) \times I_{i}^{\text {ref }} \text { with } a_{j}=0.1 \times j \\
& \quad \text { for } i=1, \ldots, 1004 \text { and } j=-10, \ldots, 10
\end{aligned}
$$

where the index $i$ denotes the spectral pixel number and $j$ the perturbation. For instance, $I_{i,-10}$ represents a perturbation on the $\mathrm{i}^{\text {th }}$ pixel of $-100 \%$ (i.e. $I_{i,-10}=0$ ), $I_{i, 0}$ is the unperturbed reference radiance $I_{i}^{\text {ref }}$, and $I_{i, 10}$ a perturbation of $100 \%$ (i.e. $2 I_{i}^{\text {ref }}$ ).

Figure 5 shows the results of this study around the $\mathrm{CO}$ fitting window $\left(4282-4303 \mathrm{~cm}^{-1}\right)$ in channel 8 . The absorption cross sections of $\mathrm{CO}, \mathrm{CH}_{4}$, and $\mathrm{H}_{2} \mathrm{O}$ are depicted in Fig. 5 (top left panel) for reference. Note that eight $\mathrm{CO}$ lines are shown, whereas only the central six are actually included 

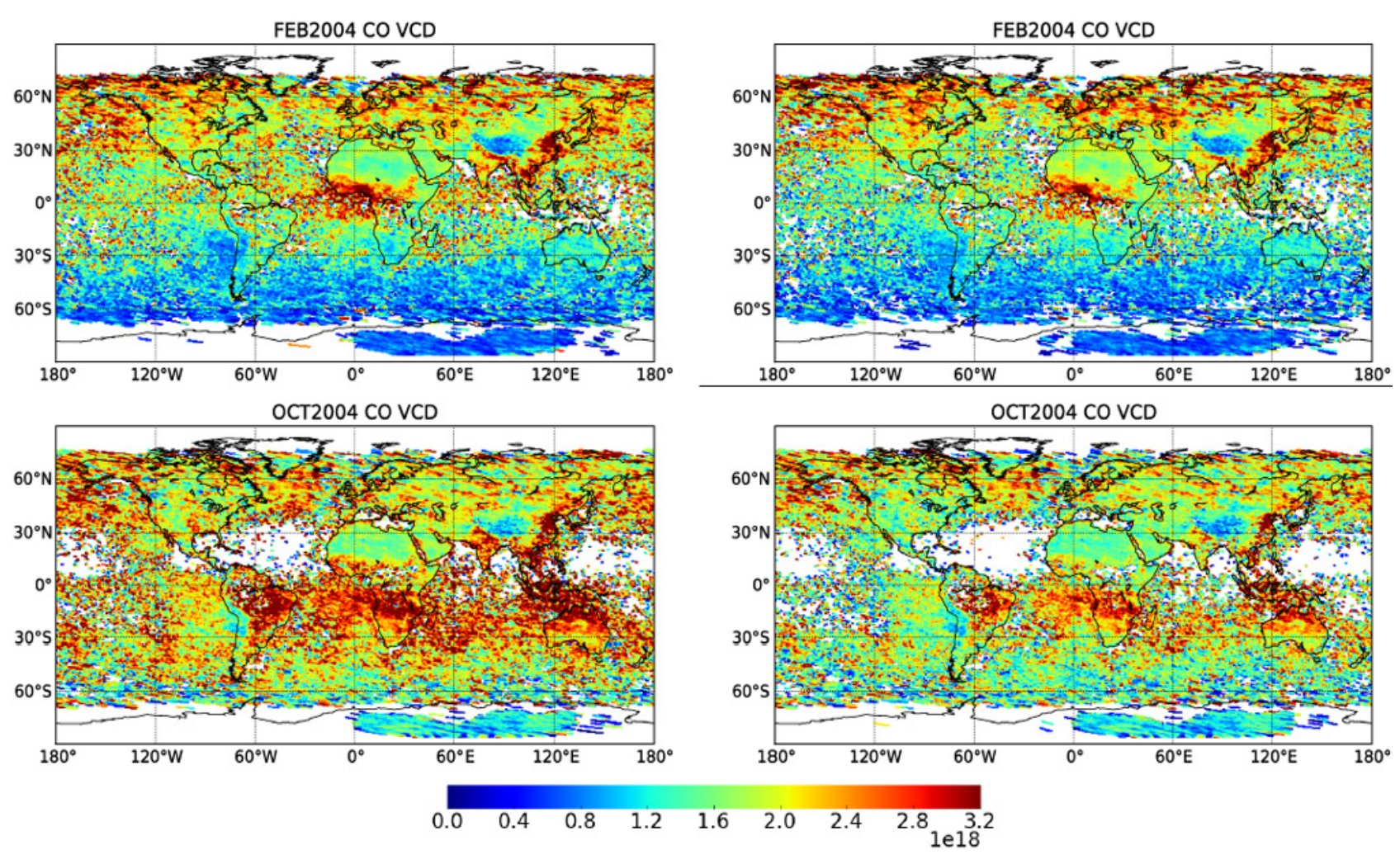

Fig. 4. Comparison of a retrieval using a constant mask flagging only pixels that are marked as "bad" for at least half of the cases of the year 2004 (left) and a retrieval using a dynamic mask appropriate for each measurement (right). In February (top) the results look similar while the result for October (bottom) is noisier for the constant mask that does not flag all bad pixels. CO VCD in units molec $\mathrm{cm}^{-2}$.

in the aforementioned fitting window. The further panels show the impact of the perturbations on the fitted molecular scaling factors $\alpha_{\mathrm{CO}}, \alpha_{\mathrm{CH} 4}$ and $\alpha_{\mathrm{H} 2 \mathrm{O}}$. The patterns of the effect of pixel perturbations on the different gas retrievals look completely different, reflecting the structure of the cross sections. Perturbations of pixels close to the center of strong absorption lines have mostly a large impact on the retrieved columns, whereas a perturbation on pixels far away in the wings does not alter significantly the retrievals. In absolute values, the effect is very different for $\mathrm{CO}$ (up to a factor 2) than for the other two gases (few percent). Both, water vapor and methane absorb substantially over the entire channel, so the perturbation of a single pixel is not critical. On the other hand, carbon monoxide has much weaker absorption lines and only in part of the channel, and consequently is more sensitive to the quality of the spectra. Indeed, some perturbations even resulted in negative CO scaling factors. Recall that for this sensitivity study, the measurement vector $\boldsymbol{y}$ comprises 1004 elements. In case of the $\mathrm{CO}$ retrieval window, the size of the measurement vector is considerably reduced and the effect of radiance perturbations on the $\alpha$ 's increases significantly (orders of magnitude for $\mathrm{CO}$ ), since individual pixels gain in relative weight. Note that for operational retrievals the fitting window cannot cover the whole channel due to the timeliness requirements on data availability.
According to Fig. 5, the effect on $\mathrm{H}_{2} \mathrm{O}$ retrievals seems to be small. However, water vapor is highly variable spatially and temporally, and the water profile assumed in the model has a strong impact on the retrieval result, cf. Fig. 6. Furthermore, molecular spectroscopy of water is quite delicate and, according to Rothman et al. (2009), "the recommended line list for water remains in a state of constant evolution." In laboratory spectroscopy, an accurate determination of the amount of water in the absorption cell is difficult, thus any error in the number density $n$ leads to a systematic error (over- or underestimate) of line strengths. For all 92 water lines in the $4280-4305 \mathrm{~cm}^{-1}$ wavenumber interval, HITRAN 2008 gives an uncertainty range between 5 and $10 \%$ for line strengths. Note that optical depth $\tau$ and transmission $\mathcal{T}$ depend on the product of line strength and number density, $S n$ (see Eqs. 3 and 4); moreover, in the lower atmosphere the line center value of the molecular absorption is proportional to $S n / \gamma_{\mathrm{L}}$ where $\gamma_{\mathrm{L}}$ is the Lorentz width. In conclusion, the uncertainty of both, water density profile and water line parameters suggests the omission of further pixels sensitive to water, i.e. those near strong $\mathrm{H}_{2} \mathrm{O}$ absorption lines possibly not modeled sufficiently well. 

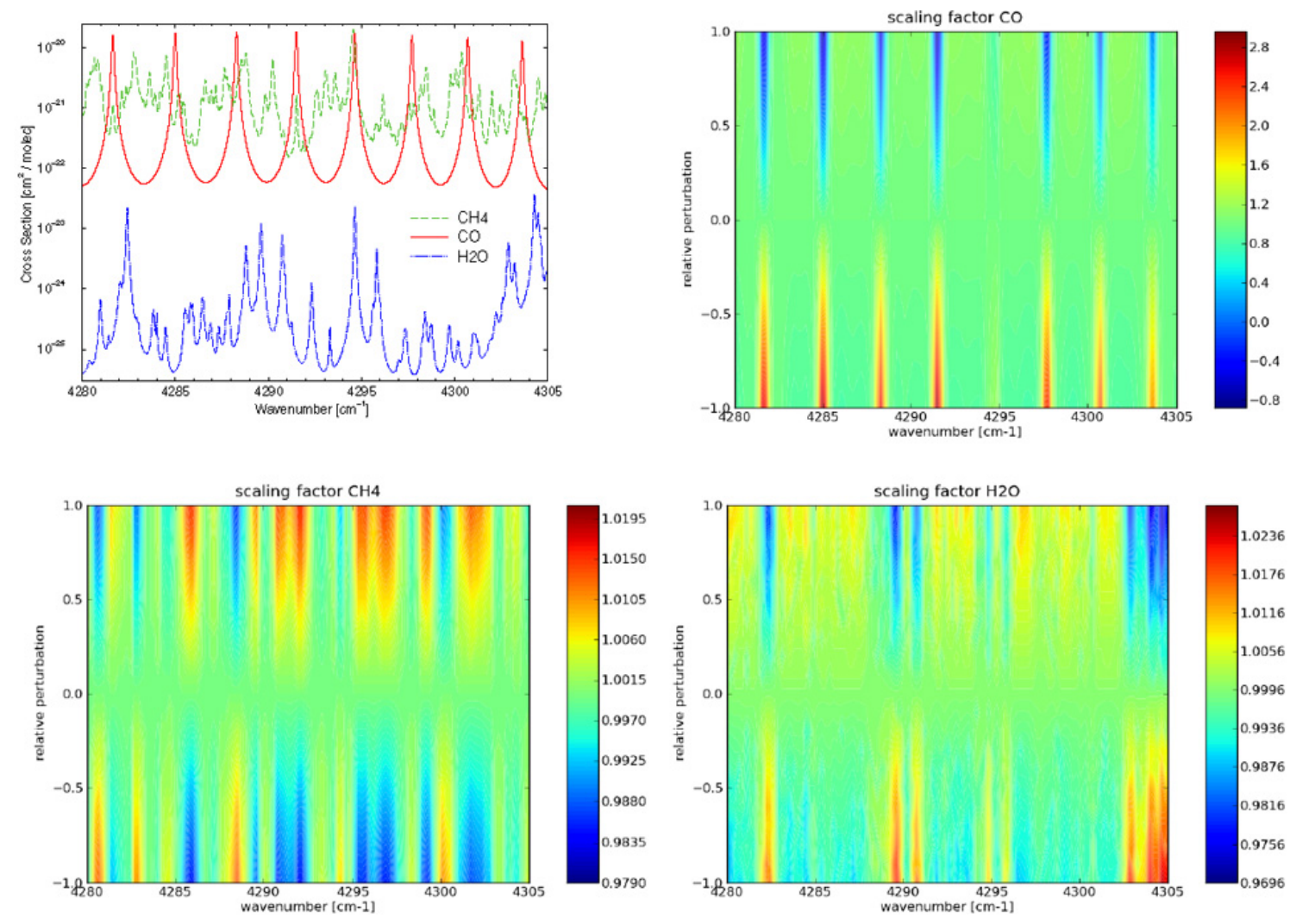

Fig. 5. Sensitivity of BIRRA CO VCDs with respect to perturbations of individual pixels. Top left: absorption cross sections of CO (red), $\mathrm{CH}_{4}$ (green dashed), and $\mathrm{H}_{2} \mathrm{O}$ (blue long dashed) in channel $8 \mathrm{CO}$ fitting window. Other plots: molecular scaling factors as a function of individual pixel perturbations. Note the different range of the color bars.

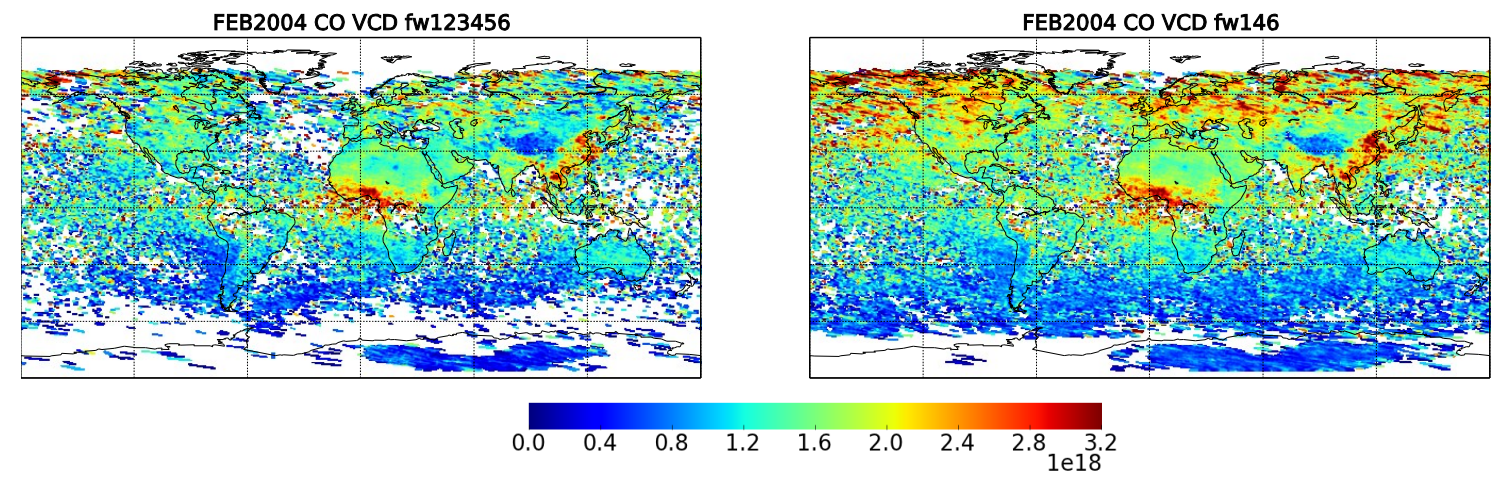

Fig. 6. Comparison of two VCD [molec $\mathrm{cm}^{-2}$ ] retrievals for February 2004. Left: all good pixels in the retrieval window are used. Right: pixels over lines with strong water vapour interference are excluded. In the latter case, several features like enhanced CO values in South-East Asia and the North-South gradient are more clearly visible.

\subsection{Ice layer and instrument transmission}

The NIR detectors of SCIAMACHY are the coldest point of the instrument. Since not all water was removed from ENVISAT during the commissioning phase, an ice layer is deposited on the detector surface (this layer is regularly removed by heating the detectors). The ice reduces the trans- mission in a wavelength dependent way; furthermore it scatters the incoming light and generally leads to a broadening of the spectrum (Lichtenberg et al., 2006; Gloudemans et al., 2005). To account for this effect in carbon monoxide retrievals from channel 8 spectra, BIRRA treats the slit function HWHM $\gamma$ as an additional auxiliary fit parameter. 


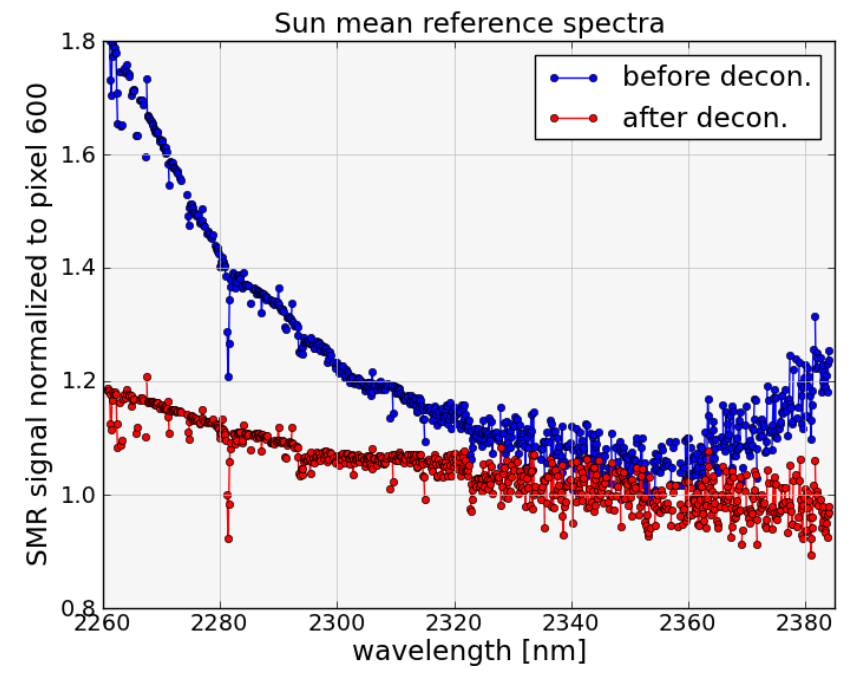

Fig. 7. Sun mean reference (SMR) spectrum in channel 8 with ice layer (blue) and with clean detector (red), normalised to the signal in an arbitrary pixel to illustrate the change in the spectral shape.

Figure 7 shows a typical sun mean reference (SMR) spectrum shortly after decontamination, i.e. with only a thin or no ice layer and a SMR spectrum several weeks later. The change of the spectral shape due to the ice extinction is clearly visible. See also Subsect. 4.1 for a discussion about the impact of the ice layer on mean instrument transmittance or throughput.

\subsection{Solar spectrum}

The solar irradiance spectrum used in the radiative transfer model, Eq. (10), also has some impact on the retrieval product. BIRRA can use the SMR spectrum measured daily (as an average of a series of measurements) by SCIAMACHY for calibration and scientific purposes. Alternatively, a variety of solar spectra models and measurements is available (e.g. Abrams et al., 1996; Hase et al., 2006), and BIRRA can read solar irradiance spectra of Kurucz (1995) (extracted from MODTRAN4, Berk et al., 1999).

Figure 8 illustrates relative differences of some selected fit parameters when using, on the one hand, the Kurucz model solar spectrum and the SCIAMACHY SMR spectrum, on the other hand. The first row shows relative differences for the $\mathrm{CO}$ scaling factor $\alpha_{\mathrm{CO}}$, the second row for the $\mathrm{CH}_{4}$ scaling factor $\alpha_{\mathrm{CH} 4}$ and the third row for xCO column density. The left column shows the results of the month February 2004 whereas the second one presents those of July 2004. Reddish color (indicating higher values of the fit values for the Kurucz spectrum compared to the SMR spectrum) dominates in all plots of Fig. 8 with no exception, i.e. the use of the $\mathrm{Ku}-$ rucz spectrum biases $\alpha_{\mathrm{CO}}, \alpha_{\mathrm{CH} 4}$ and $\mathrm{xCO}$ to higher values. Note, however, that the color bar of $\alpha_{\mathrm{CH} 4}$ ranges from -0.1 to $0.1( \pm 10 \%)$, whereas that of $\alpha_{\mathrm{CO}}$ and $\mathrm{xCO}$ ranges from
-0.5 to $0.5( \pm 50 \%)$. Thus, the impact of the solar spectrum is much higher on $\mathrm{CO}$ than on $\mathrm{CH}_{4}$. The difference distributions of $\alpha_{\mathrm{CH} 4}$ are quite homogeneous, with the exception of the Tibetan Plateau and the Andes Cordillera, where the differences increase. The distributions of $\alpha_{\mathrm{CO}}$ and $\mathrm{xCO}$ are very similar indicating that the effect of the solar spectrum on $\mathrm{xCO}$ is caused basically by the effect of the solar spectrum on $\alpha_{\mathrm{CO}}$ rather than on $\alpha_{\mathrm{CH} 4}$. The $\mathrm{CO}$ difference distributions show latitude (solar zenith angle) as well as seasonal dependency (the pattern in February and July differ considerably).

Since SMR and Earth's spectra are measured with the same detector, most artificial features are included in both spectra. This is an advantage of SCIAMACHY's SMR spectrum with respect to Kurucz or any other solar spectrum, since in the latter cases, artifacts in Earth's spectra would be attributed by the model to atmospheric effects. As a consequence SCIAMACHY's SMR spectra are used in the retrievals.

\subsection{Spectral calibration}

In order to ensure high spectral stability over the lifetime of the mission, SCIAMACHY has been equipped with a spectral calibration lamp, the "Spectral Line Source" (SLS), for determining the pixel-to-wavelength relationship. Whereas the SLS has proved to be suitable for a precise in-flight spectral calibration of channels 1 to 6 , it is not sufficient for the calibration of channel (7 and) 8 due to the lack of enough SLS spectral lines within these channels. Because of this, the pixel-to-wavelength relationship of channel 8 in the level-1b product is set to the on-ground calibration. Although onground calibration was performed under representative flight conditions (temperature and vacuum), a similar spectral tuning as in the other channels should be applied to channel 8 for a precise spectral calibration.

Information from molecular spectroscopy (as provided by the HITRAN or GEISA database) can be exploited for spectral calibration, i.e. an in-flight spectral calibration for the SCIAMACHY channel 8 can be performed utilizing absorption signatures of atmospheric methane, water vapor and carbon monoxide. The spectral correction found has roughly a second-degree polynomial dependency and its value can be as large as $0.5 \mathrm{~nm}$ (more than 4 pixels) at the right edge of channel 8, see Fig. 9. Within the CO fitting window, the spectral correction is well approximated by a first-degree polynomial, i.e. shift and squeeze.

As shown in Fig. 10, the neglect of an appropriate wavelength calibration leads to negatively biased VCD distributions (note the different color bars) and unrealistic regional patterns (e.g. Himalayas). 

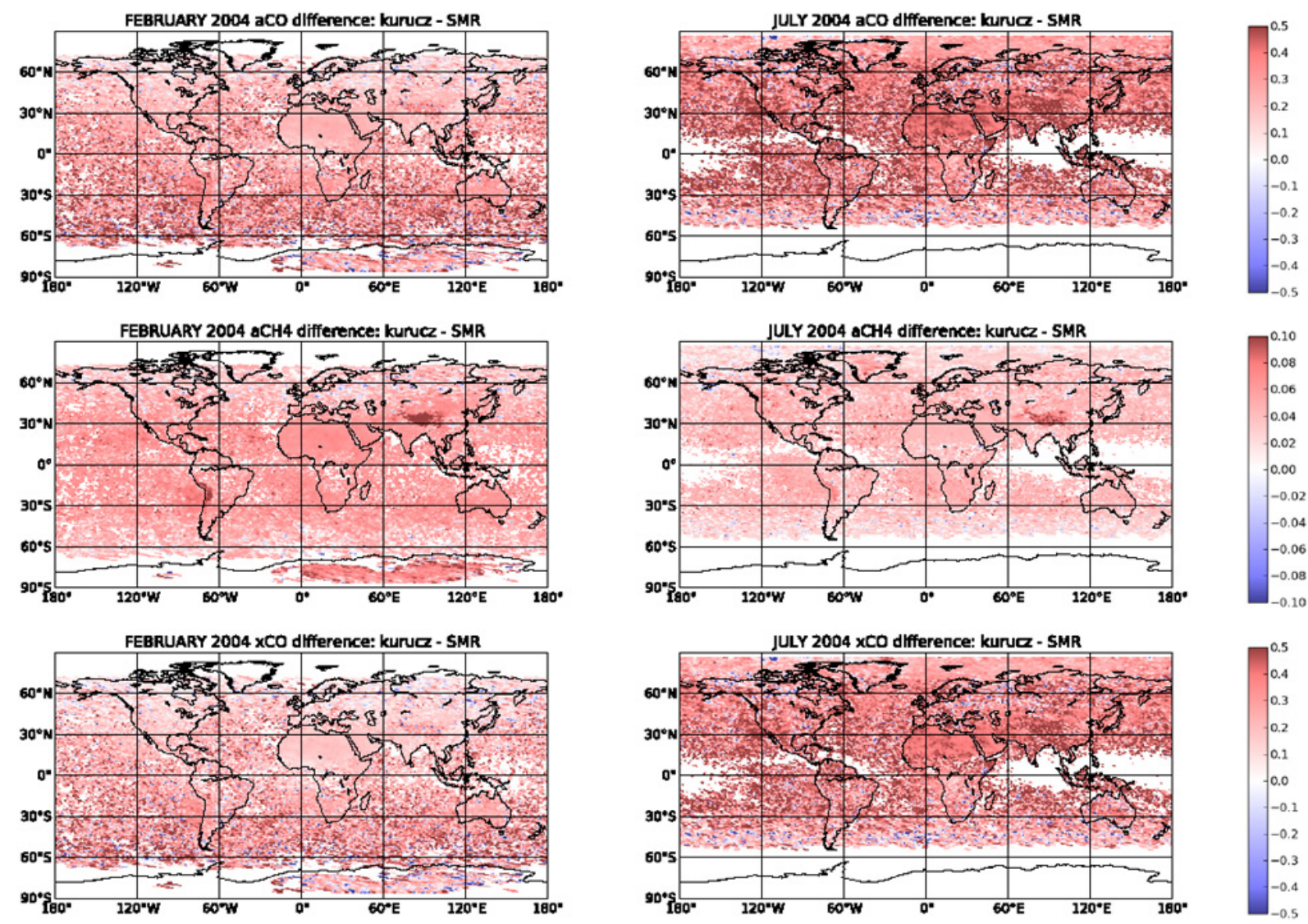

Fig. 8. Influence of the solar spectrum on monthly average $\mathrm{CO}$ retrievals. The plots show relative differences of $\alpha_{\mathrm{CO}}$ (top), $\alpha_{\mathrm{CH} 4}$ (mid), and xCO (bottom) of retrievals with the Kurucz solar spectrum vs. the SCIAMACHY SMR spectrum for two months in 2004: February (left) and July (right).

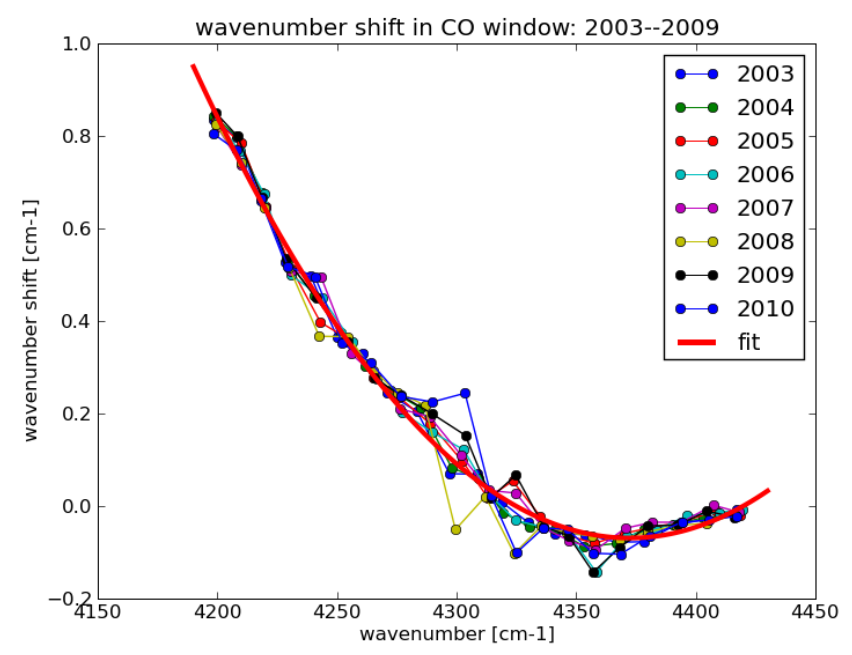

Fig. 9. Spectral correction to the on-ground pixel-to-wavelength relationship.

\subsection{Spectroscopic input data: line parameters and continuum}

Spectroscopic line parameter databases such as HITRAN (Rothman et al., 2009) or GEISA (Jacquinet-Husson et al., 2008) are an essential input for the computation of molecular cross sections (Eq. 4). Recently, Frankenberg et al. (2008a,b) have discussed the importance of accurate and complete line parameters for methane retrievals in SCIAMACHY channel 6. In the short-wave end of SCIAMACHY channel 8, water vapor spectroscopic data are significantly different in the recent version of these databases. Feng and Zhao (2009) discusses impacts of changes of the HITRAN database on near infrared transmittances, and in SCIAMACHY's channel 8 found the most noticeable changes for wavenumbers larger than $4350 \mathrm{~cm}^{-1}$. In the middle of this channel used for $\mathrm{CO}$ retrievals, there are only minor changes, and the retrievals do not show a strong impact.

The default setting for the retrieval of CO column densities from SCIAMACHY channel 8 considers three absorbers, i.e. $\mathrm{CO}, \mathrm{CH}_{4}$, and $\mathrm{H}_{2} \mathrm{O}$. Although there are no $\mathrm{CO}_{2}$ lines in the center of channel 8 , there is a contribution of a small, yet 

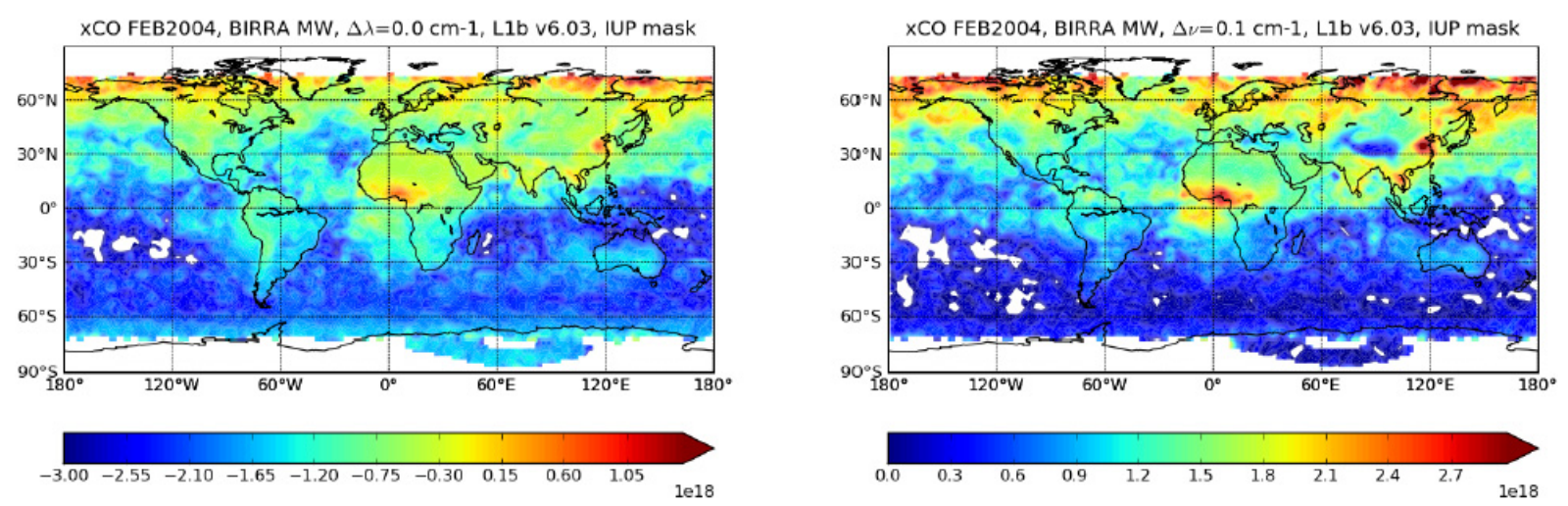

Fig. 10. Comparison of $x C O$ retrievals without (left) and with wavenumber calibration. Note the different color bar with $x C O$ values ranging down to $-3 \cdot 10^{18}$ molec $\mathrm{cm}^{-2}$ for the unshifted wavenumber retrievals (left). (DBPM provided by M. Buchwitz, personal communication, October 2006).

non-vanishing $\mathrm{CO}_{2}$ continuum. However, adding $\mathrm{CO}_{2}$ as an additional absorber has a negligible effect on the retrieved $\mathrm{xCO}$ product.

\subsection{Atmospheric input data}

VCDs are retrieved in BIRRA by fitting the scaling factors $\alpha_{m}$ of concentration profiles $n_{m}(z)$ (see Eqs. 1, 8). Accordingly, the quality of the retrieval clearly depends on the adequacy of the profiles used. Furthermore, pressure and temperature data are required to evaluate the molecular cross sections $k(v, p, T)$ in Eq. (4). Test retrievals for orbit 8663 using the six AFGL model atmospheres (Anderson et al., 1986) reveal that the fitted CO column densities are especially sensitive to temperature.

Clearly, the use of just a few atmospheric profiles (as provided by the AFGL data) does not really cover the full seasonal and spatial variability. There are different strategies to better represent the atmospheric state in the retrievals: Buchwitz et al. (2004) use a single profile of temperature, pressure, and trace gas mixing ratios from the US Standard atmosphere (with methane scaled to $1750 \mathrm{ppbv}$ ), and fits an additional temperature shift parameter to account for the temperature dependence of the molecular absorption cross sections. In Gloudemans et al. (2008), temperature and $\mathrm{H}_{2} \mathrm{O}$ profiles are taken from the European Centre for MediumRange Weather Forecasts (ECMWF).

Because molecular cross sections are computationally expensive and operational processing imposes timeliness constraints, BIRRA uses a compromise and takes a single pressure and temperature profile for each state selected from the CIRA-86 data base according to time and mean latitude. The Committee on Space Research (COSPAR) International Reference Atmosphere (CIRA) provides monthly mean profiles of pressure vs. temperature for the altitude range $0-120 \mathrm{~km}$ with almost global coverage $\left(80^{\circ} \mathrm{N}-80^{\circ} \mathrm{S}\right)$ (Fleming et al.,
1990, http://badc.nerc.ac.uk/data/cira/). Trace gas profiles are taken from the US Standard Atmosphere.

\subsection{Least squares settings}

Solvers for nonlinear least squares problems usually offer several input parameters to control the iterations. In addition to termination code due to excessively large number of iterations, the PORT library delivers convergence codes for standard $x$-tolerance (relative change of the norm of the $x$ state vector) and $y$-tolerance (relative change of the norm of the residual vector $\boldsymbol{y}-\boldsymbol{F}(\boldsymbol{x}))$ (Gay, 1990). In our applications, "relative function convergence" was reached for most of the cases.

Ideally, the different least squares solvers provided by PORT should give identical retrieval results. Figure 11a shows that the retrieved carbon monoxide VCDs (averaged within a $1 \mathrm{dg}$ latitude belt over all longitudes) of orbit 8663 (27 October 2003) are very similar for all methods. Differences can be expected for "difficult" observations, i.e. when the fit did not converge properly or some of the fitted parameters are exceptionally small or large. Especially in case where the iterative optimization algorithm suggests a step leading to one or several negative fit variables, differences show up in the constrained and unconstrained retrievals. In fact, the spikes around $20^{\circ} \mathrm{N}$ and $32^{\circ} \mathrm{S}$ do not show up in both constrained least squares results. Various strategies have been discussed, how an algorithm should proceed when some of the physical variables reach "forbidden" (usually negative) values; common approaches are to stop the iterative solution process, or to ignore and continue (and accounted for in the post-processing of the data). In case of unconstrained least squares fits, BIRRA stops the iteration when it encounters negative slit function widths or in case of too many negative scaling factors.

Separable least squares is slightly faster than the nonlinear least squares. The main advantage is the numerical 
robustness and reliability of the separable least squares: using synthetic "observed spectra" with constant reflectivity $\left(r_{0}>0, r_{1}=r_{2}=0\right)$ and fitting with a second order reflectivity polynomial, the separable least squares delivers the "true" state vector (molecular scaling factors and auxiliary parameters) correctly in all cases, whereas the nonlinear least squares fails for about half of the spectra.

\section{Carbon monoxide and methane vertical column densities - a survey}

Despite the challenges of nadir NIR retrievals, SCIAMACHY observations can be used to estimate time averaged distributions of carbon gas vertical column densities. In the following subsections, a survey of BIRRA carbon monoxide retrieval results is given, followed by a brief presentation of first BIRRA methane retrievals.

\subsection{Monitoring of fit parameters}

In the previous subsections, the impact of the level $1 \mathrm{~b}$ data quality on carbon monoxide retrievals has been discussed. Fig. 12 and 13 illustrate time series of the fit parameters for CO retrievals in channel 8. The panels of Fig. 12 show, from top to bottom, the mean channel transmission (throughput), the scaling factors of $\mathrm{CO}, \mathrm{CH}_{4}$ and $\mathrm{H}_{2} \mathrm{O}$, the HWHM of the instrument slit function, and the zeroth, first, and second degree coefficients of the albedo polynomial. Although the throughput is not a fit parameter, it has been included here for comparison. Because of the difficulty in modeling the ice layer on top of channel 8 , it has an impact on the fitted parameters.

Since the ice layer reduces the mean intensity, the throughput (the mean instrument transmission) is a good indicator of its thickness. Table 1 shows the cross-correlation $\rho$ of the different fit parameters with respect to the throughput. Note that these coefficients are calculated for the 14-days averaged time series, not for individual observations. They are normalized between -1 (full anti-correlation) and 1 (full correlation). A high correlation coefficient (in absolute value) means that the two curves follow a similar course and it will be taken here as evidence for a possible causal relationship. Table 1 illustrates that (the scaling factor of) $\mathrm{CH}_{4}$ is the most affected parameter by the ice layer growth. The second degree polynomial coefficient $r_{2}$ has the second highest correlation, suggesting that the normalization of the observed spectra by the SMR spectrum does not completely eliminate the change in spectral shape due to scattering in the ice layer. These conclusions are backed by Fig. 12. According to Tab. 1, the first degree polynomial parameter $\left(r_{1}\right)$, the HWHM and CO are less affected by the ice layer. A detailed examination of the curves in Fig. 12, however, shows that $r_{1}$ does have a strong anti-correlation with the throughput, but two outliers lower the value of $\rho$. Remarkably, the $r_{0}$ coefficient shows little correlation with the throughput. Using an external (constant) solar spectrum, a reduction of the instrument transmission would likely be interpreted as a reduction of albedo by the model. However, by using the measured SMR, the dependency of the albedo on the throughput is effectively reduced. $\mathrm{H}_{2} \mathrm{O}$ shows almost no impact of the ice layer $(\rho \sim 0)$ and the seasonal variation is clearly seen. Notice that the HWHM continuously increases with time, which may be an indication of general degradation of the instrument.

Since the ice layer affects $\mathrm{CO}$ and $\mathrm{CH}_{4}$ differently, the use of $\mathrm{xCO}$ as estimator of the "true" CO VCD does not remove the impact of the ice layer and the results will be affected accordingly.

The time series in Fig. 13 show a general trend of increasing fit errors indicating that the results become continuously worse. Since the model remains the same, this can only be interpreted as a decrease of the measurement quality. The curves also show some time intervals with exceptionally high errors, e.g. June 2006 and 2007, most likely due to the incorporation of some bad pixels in the fit.

\subsection{Carbon monoxide}

Carbon monoxide is an important trace gas affecting air quality and climate. Although $\mathrm{CO}$ is not considered as a greenhouse gas, it is relevant as a precursor for carbon dioxide. $\mathrm{CO}$ is also one of the major precursors of tropospheric ozone. It is highly variable in space and time. In the troposphere, about half of the $\mathrm{CO}$ originates from anthropogenic sources (e.g. fossil fuel combustion), and further significant contributions are due to biomass burning. With its photochemical lifetime of one to three months, $\mathrm{CO}$ is a good tracer of transport in the troposphere as well as in the strato- and mesosphere.

With passive atmospheric remote sensing, carbon monoxide can be observed in several spectral regions from the microwave to the near infrared. $\mathrm{CO}$ is a target species of several spaceborne instruments, nb. AIRS (McMillan et al., 2005, 2008), MOPITT (Deeter et al., 2003, 2009), and TES (Rinsland et al., 2006) from NASA's nadir sounders aboard the EOS satellite series; MIPAS and SCIAMACHY on ESA's Envisat, and more recently it has also been observed by IASI on MetOp (Fortems-Cheiney et al., 2009; George et al., 2009; Illingworth et al., 2011).

\subsubsection{Retrieval errors}

The error of the proxy normalized VCD, Eq. (1), is estimated from the errors of the column scaling factors $\alpha_{\mathrm{CO}}$ and $\alpha_{\mathrm{CH} 4}$, that, in turn, are obtained from the diagonal elements of the least squares covariance matrix defined by

$$
\Xi=\sigma^{2}\left(J^{\mathrm{T}} J\right)^{-1} \quad \text { with } \quad \sigma^{2}=\|\boldsymbol{y}-\boldsymbol{F}(\boldsymbol{x})\|^{2} /(m-n)
$$



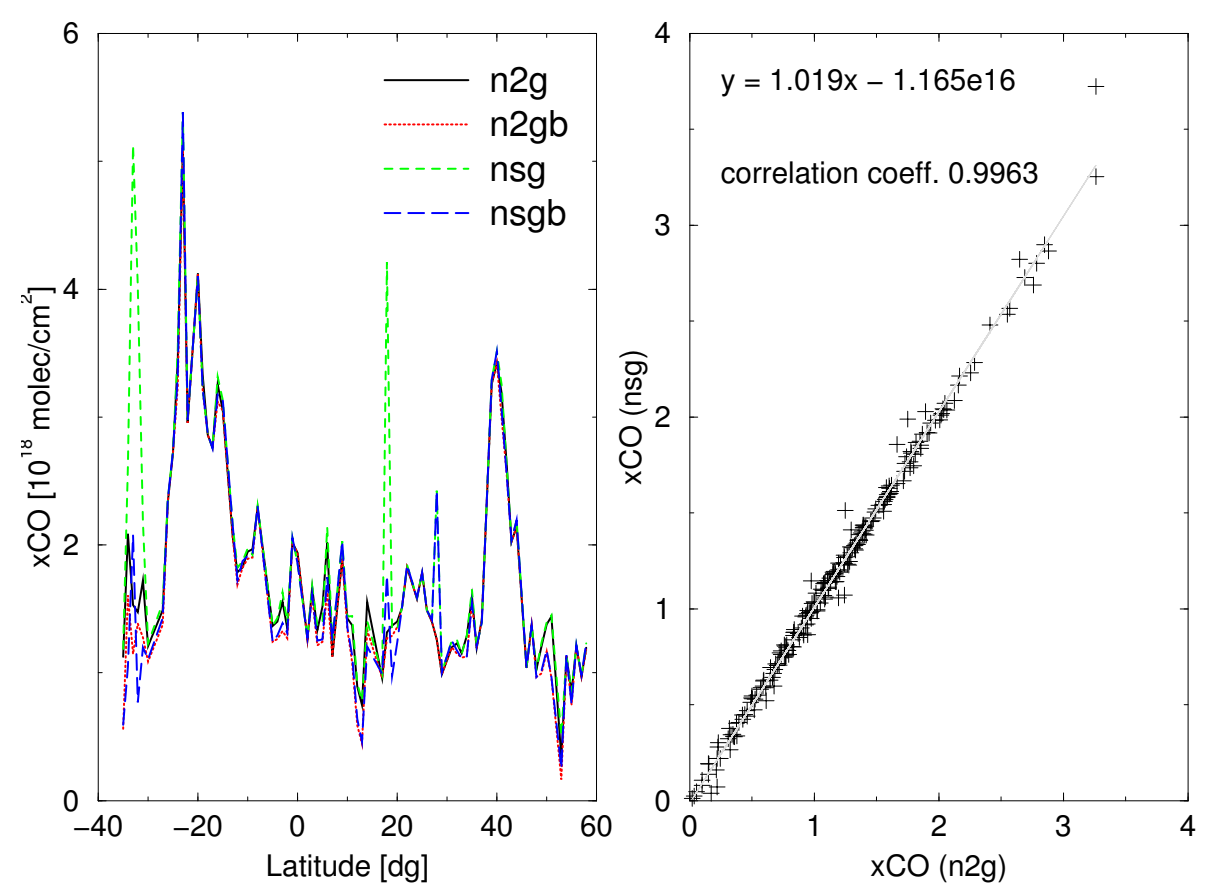

Fig. 11. Sensitivity of CO retrievals with respect to least squares algorithm for orbit 8663 (27 October 2003, covering Russia, the Arabic peninsula, and Eastern Africa): (a) comparison of $\mathrm{CH}_{4}$-normalized $\mathrm{CO}$ vertical columns (xCO). "n2g" and "nsg" denote nonlinear and separable least squares, respectively; "b" indicates the bound constrained versions. (b) Scatter plot of xCO retrieved using nonlinear least squares ("n2g", horizontal axis) vs. separable least squares ("nsg", vertical axis).

Table 1. Cross correlation coefficients $\rho$ between fit parameters and throughput.

\begin{tabular}{lccccccc}
\hline parameter & $\mathrm{CO}$ & $\mathrm{CH}_{4}$ & $\mathrm{H}_{2} \mathrm{O}$ & HWHM & refl0 & refl1 & refl2 \\
\hline correlation with throughput & 0.374 & 0.701 & 0.044 & -0.399 & 0.257 & -0.401 & 0.526 \\
\hline
\end{tabular}

where $J$ denotes the Jacobian (Gay, 1990). Note that the scaled residual norm $\sigma^{2}$ contains both, errors due to instrumental noise and deficiencies of the forward model.

Since the spectral information on carbon monoxide in the observed spectrum is small, the retrievals are specially sensitive to instrumental noise. The signal-to-noise ratio depends on the surface (or cloud) albedo and solar irradiance (essentially SZA), hence dark areas and high latitudes are expected to have higher retrieval errors. Since in most of the cases the $\mathrm{CO}$ information is comparable or even lies under the noise level, the precision of the individual estimates is low and it is customary to deliver the $\mathrm{CO}$ retrievals as spatial and temporal averages on a regular longitude/latitude grid.

Deficiencies of the forward model introduce systematic errors to the $\mathrm{CO}$ estimates. One of the major assumptions in BIRRA is the neglect of scattering within the atmosphere. Homogeneous aerosol and cloud (e.g. low marine stratocumuli) layers are satisfactorily accounted for by proxy modeling. However, under highly convective conditions, cloud heterogeneity can cause large retrieval errors.
Figure 14 shows the spatial distribution of seasonally gridded xCO retrieval errors, averaged over the period 2003 to 2005. Note that the gridded errors represent the mean value of the individual retrieval errors and not the error associated with the spatial-temporal averaged $\mathrm{xCO}$ estimate. In this manner, it is possible to visualize the dependence of the retrieval errors on time (seasons) and location. Moreover, the contributions to retrieval errors can be identified taking into account extra information, like surface albedo and climatology. Regions where surface albedo is high (e.g. Sahara, Arabian Peninsula, Australia) exhibit low xCO errors (typically lower than $5 \cdot 10^{17}$ molec $\mathrm{cm}^{-2}$ ). Analogously, regions with permanent homogeneous marine stratocumuli with high albedo (e.g. South-East Atlantic, Pacific west of Peru and California) also have associated low xCO errors. These findings are in accordance with the number of accepted observations depicted in Fig. 15, i.e. a large number of observations survive the quality screening under ideal retrieval conditions. On the other hand, systematic errors due to the presence of highly inhomogeneous convective clouds dominate the $\mathrm{xCO}$ errors. In particular, the highest retrieval errors are found 


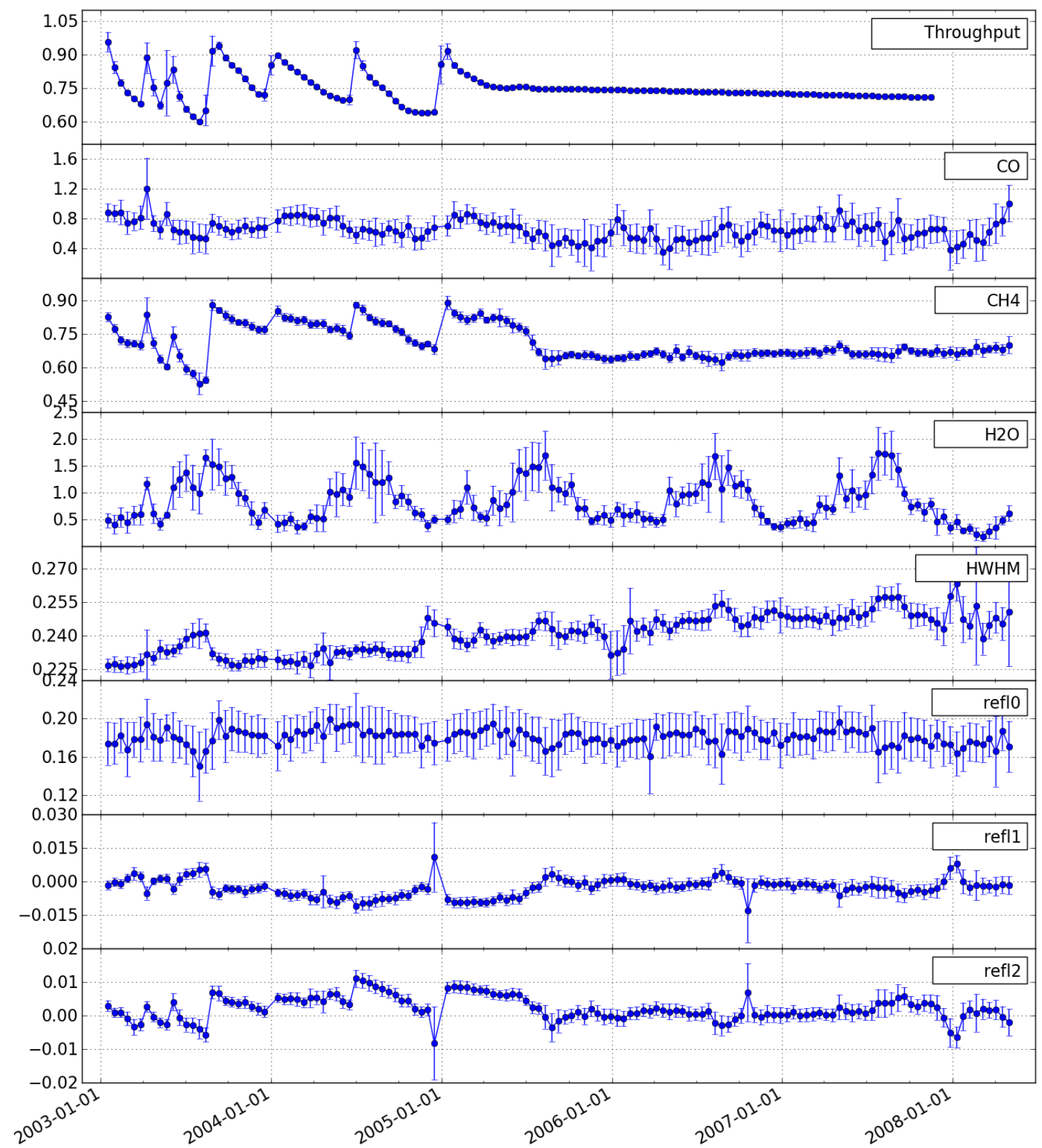

Fig. 12. Time series of 14-day averaged fit parameters included in CO retrievals from channel 8 . From top down: the mean channel transmission (throughput), the scaling factors of $\mathrm{CO}, \mathrm{CH}_{4}$ and $\mathrm{H}_{2} \mathrm{O}$, the half width at half maximum of the instrument slit function, and the zeroth, first, and second degree coefficients of the albedo polynomial. See the dependency of some parameters on throughput.

over the Indian Ocean and West Equatorial Pacific during the Asian Monsoon period (from June to September, see bottom left summer panel in Fig. 14). Accordingly, only few observations pass the quality filter, see Fig. 15.

The histograms in Fig. 16 illustrate the occurrence frequency of xCO errors, i.e. the unnormalized error probability density function (PDF). The errors are slightly higher in summer (right panel) than in winter (left panel), which is reflected by the median values and in accordance with Fig. 14 .

\subsubsection{Spatial distributions}

CO vertical columns have been processed for several years from 2003 to 2009 using the BIRRA algorithm and a dynamic bad \& dead pixel mask (see Subsect. 3.2). Figure 17 shows the annual mean of $\mathrm{CO}$ vertical columns for the years 2003, 2004, and 2005. In addition to the selection criteria mentioned in Sect. 2.3, the relative errors of retrievals (errors of $\alpha_{\mathrm{CO}}$ less than $50 \%$, error of $\alpha_{\mathrm{CH} 4}$ less than $1 \%$ ) are 


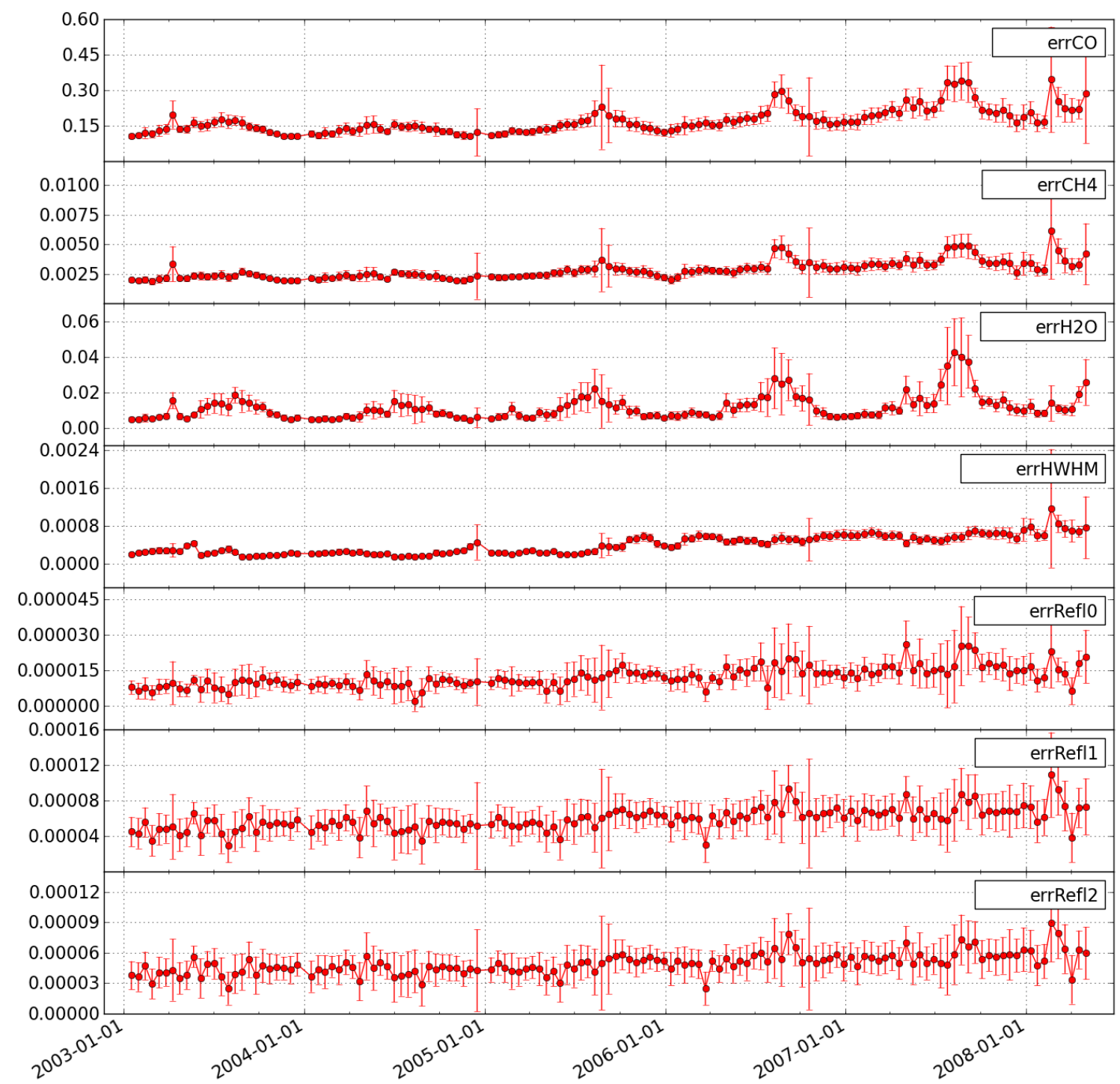

Fig. 13. Time series of 14-day averaged errors of fit parameters (see Fig. 12). From top down: error of the scaling factors of $\mathrm{CO} \mathrm{CH}_{4}$ and $\mathrm{H}_{2} \mathrm{O}$, the half width at half maximum of the instrument slit function, and the zeroth, first, and second degree coefficients of the albedo polynomial.

taken into account. All annual averages show high densities at South East Asia due to anthropogenic emissions and in Central Africa due to high density of biomass burnings during the dry seasons. It can be also noticed that the $\mathrm{CO}$ column densities were specially high during 2003. This CO increase in 2003 is related to the increase in biomass burnings during this year, and has also been reported by other studies (e.g. Buchwitz et al., 2007).

Figure 18 provides a closer look to the African continent. In this case, the results are presented as a three year average of the four seasons. Inter-tropical regions are the areas showing higher seasonality. The weather in the tropical region of the Earth is highly influenced by the tropical rain belt, which oscillates between the Northern and
Southern Hemisphere. In the Northern Hemisphere, the wet season comprises roughly the months from April to September, whereas the dry season lasts from October to March. Due to the rain bell oscillation, in the Southern Hemisphere the wet and dry seasons are reverted. During the dry season, biomass burning events are more likely to occur. The seasonality of the fires can be clearly seen in the carbon monoxide distributions: the inter-tropical regions present the highest CO VCDs at the end of the dry seasons (JanuaryFebruary-March in the northern and July-August-September in the Southern Hemisphere).

Figure 19 illustrates the three-year average of xCO over Southeastern Asia. Regions with a high population density such as the Sichuan Basin (Red Basin) in South-West 

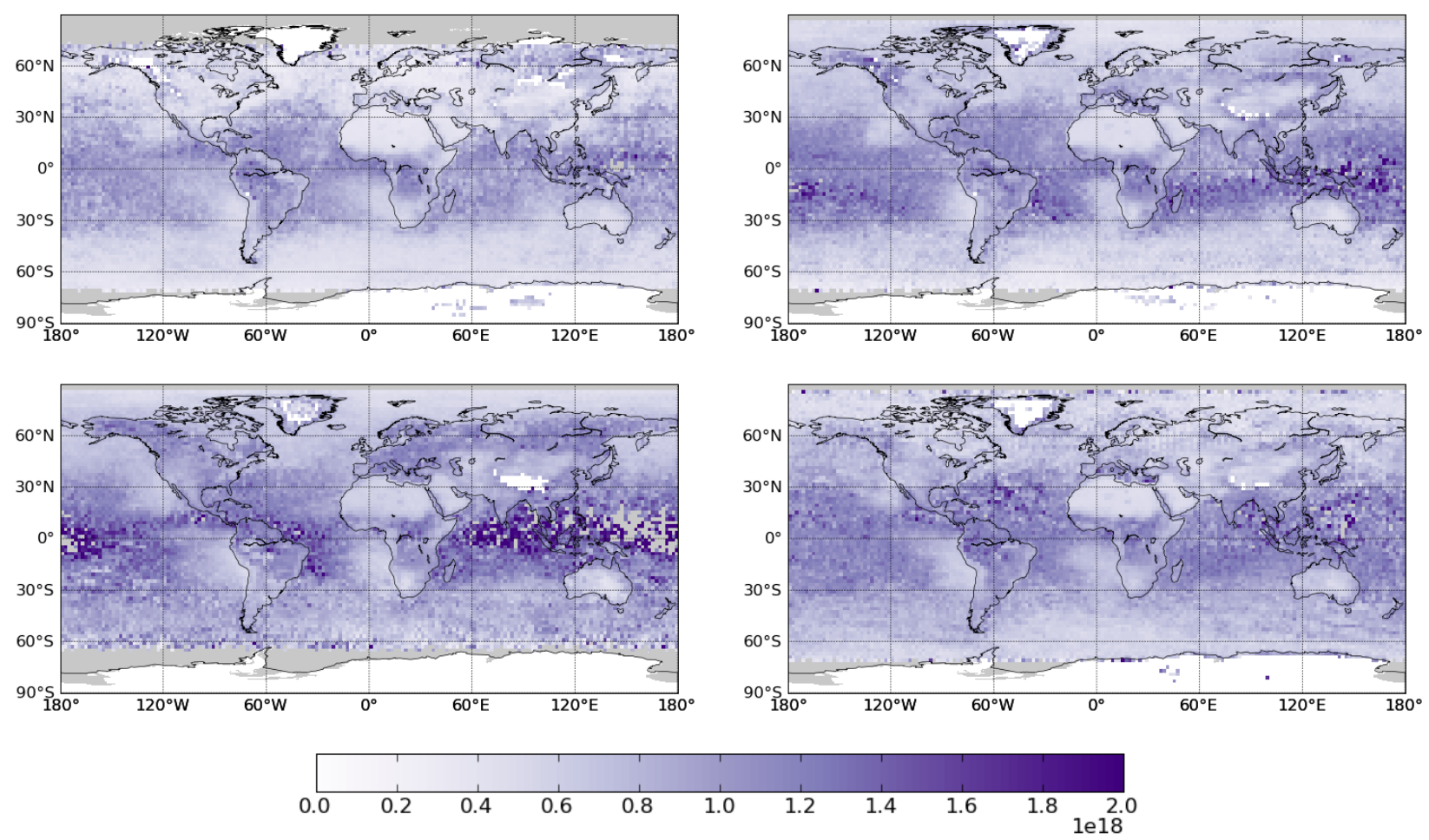

Fig. 14. xCO mean errors $\left[\mathrm{molec} \mathrm{cm}^{-2}\right]$ averaged over the four seasons 2003-2005. Top-left: December-January-February, top-right: March-April-May, bottom-left: June-July-August, bottom-right: September-October-November.
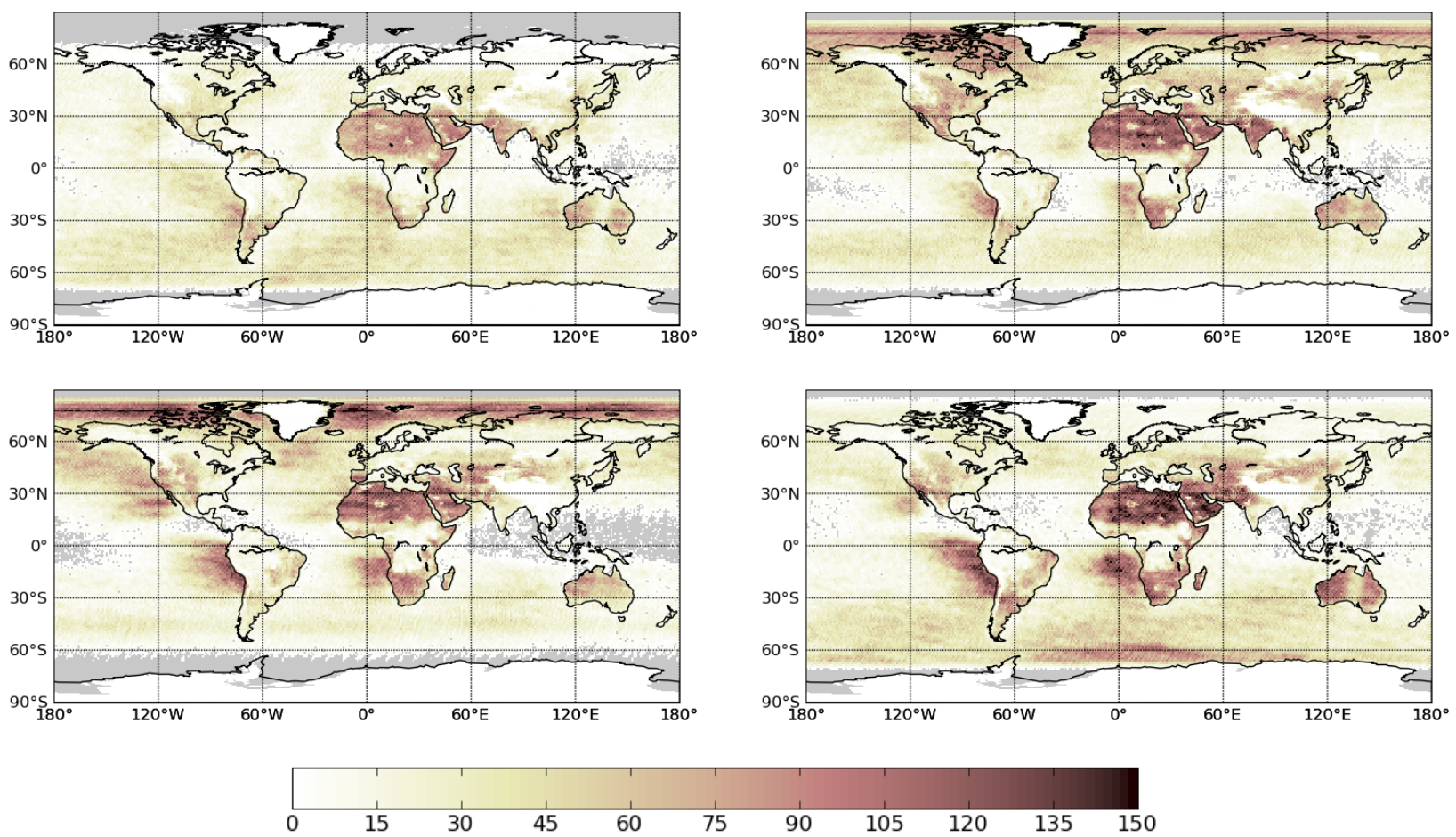

Fig. 15. Number of observations accepted for carbon monoxide VCD retrievals, seasonal three-year averages (arrangement as in Fig. 14). 

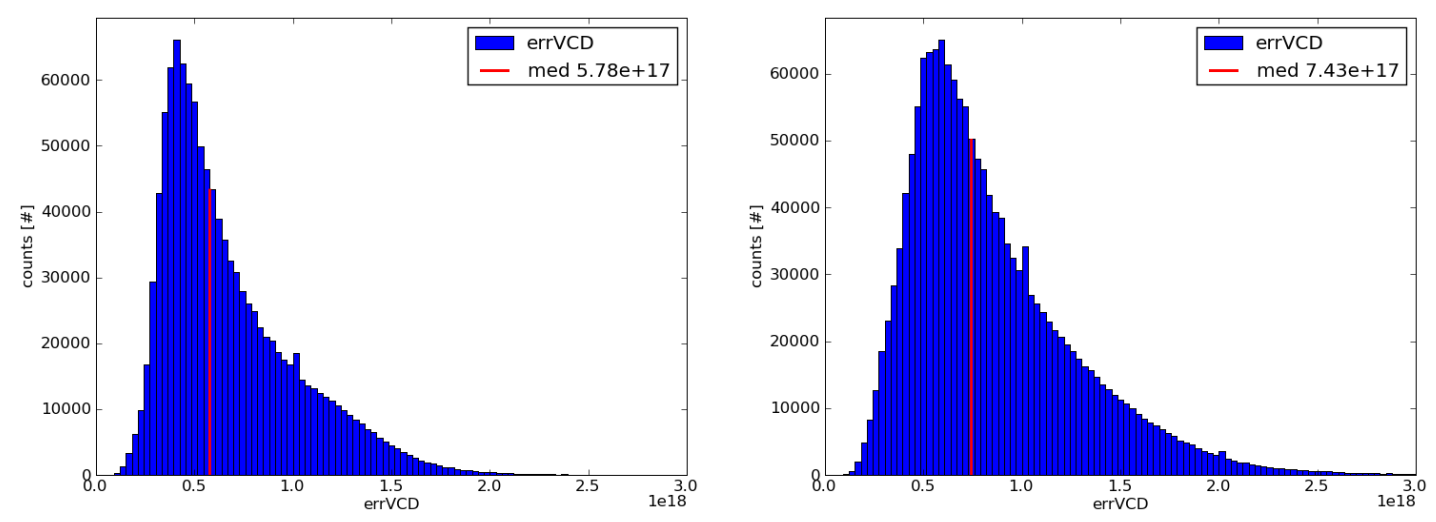

Fig. 16. Histograms of carbon monoxide vertical column density errors, three-year (2003-2005) seasonal averages. Left: winter; right: summer.
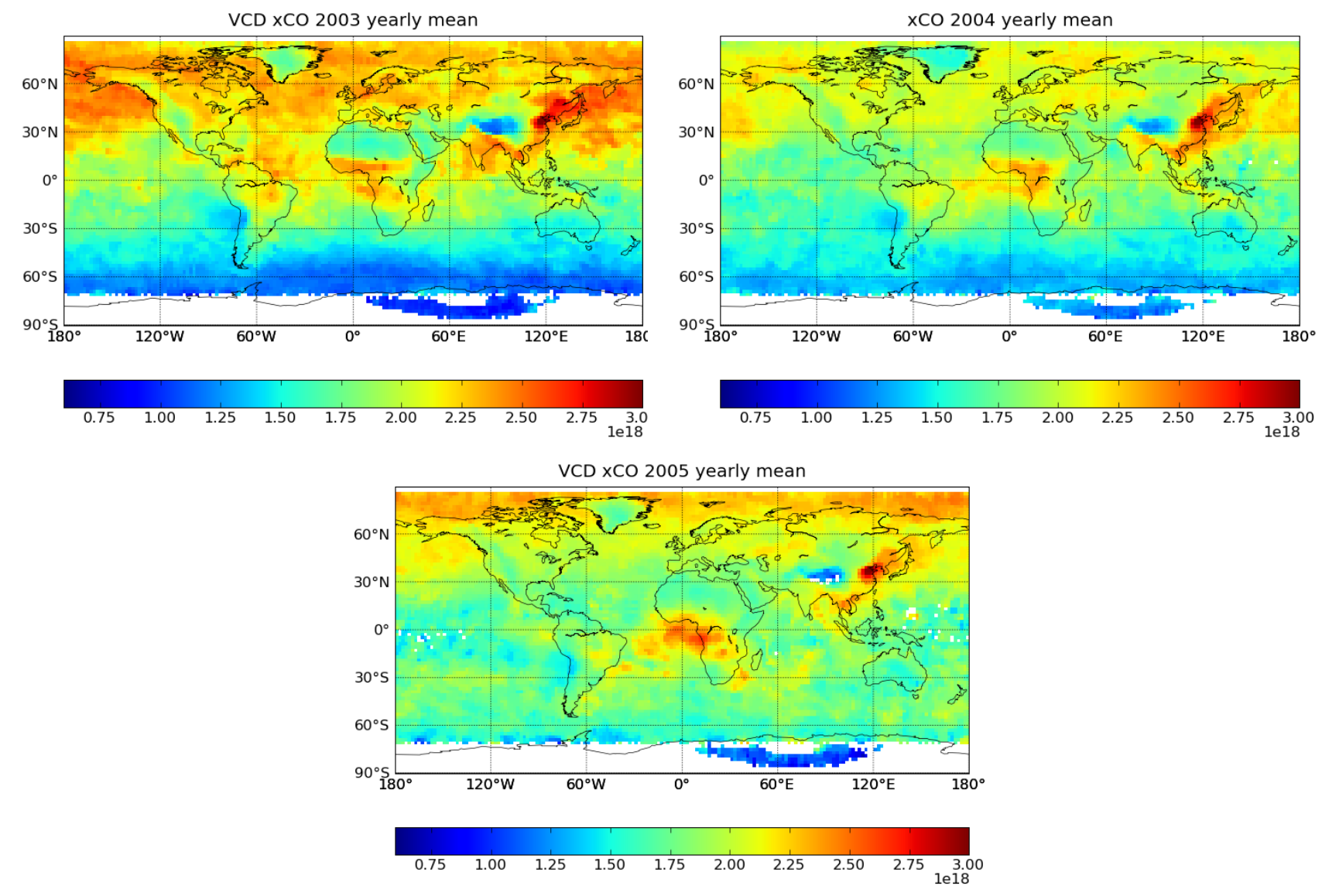

Fig. 17. Annual mean carbon monoxide vertical column densities $\left[\right.$ molec $\mathrm{cm}^{-2}$ ] for 2003 to 2005 . $\left(1^{\circ} \times 1^{\circ}\right.$ grid with $3^{\circ} \times 3^{\circ}$ median filter smoothing)

China or the Chinese eastern coast area are clearly visible with a high carbon monoxide abundance, as was already observed by, e.g. SCIAMACHY (Buchwitz et al., 2006; Gloudemans et al., 2009) and the MOPITT mission (Clerbaux et al., 2008).

\subsubsection{Intercomparison with ground-based observations}

Validation of satellite measurements is frequently performed by intercomparisons with ground-based observations. For example, Sussmann and Buchwitz (2005) have compared column CO measured by SCIAMACHY over Central Europe with Fourier Transform InfraRed (FTIR) profile retrievals at the NDACC Zugspitze station. In an extensive study, 

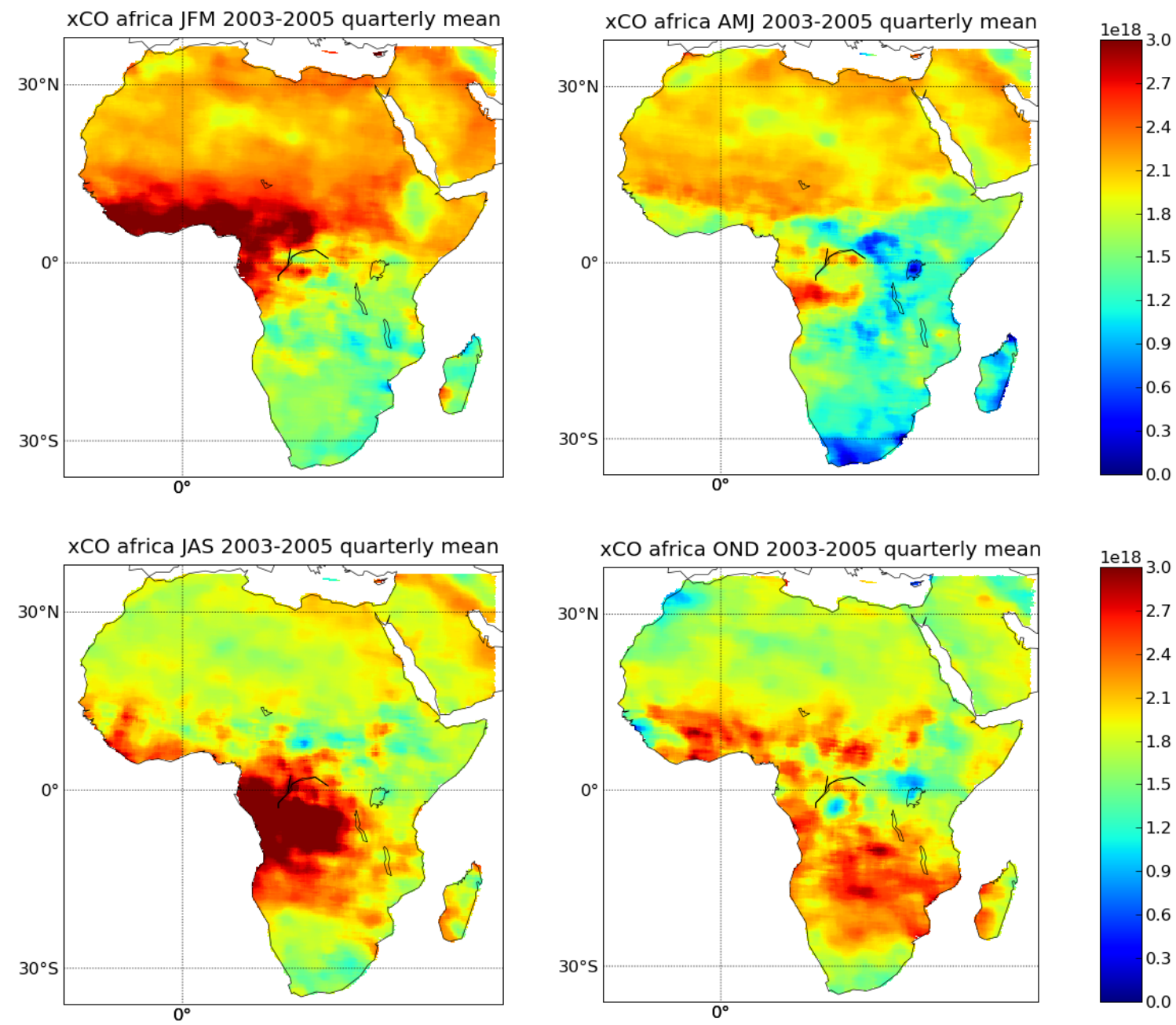

Fig. 18. Three year averages (2003-2005) of quarterly mean CO VCDs [molec $\mathrm{cm}^{-2}$ ] over Africa. From top-left to bottom-right: JanuaryFebruary-March, April-May-June, July-August-September, and October-November-December. $\left(0.2^{\circ} \times 0.2^{\circ}\right.$ grid with $1^{\circ} \times 1^{\circ}$ median filter smoothing)

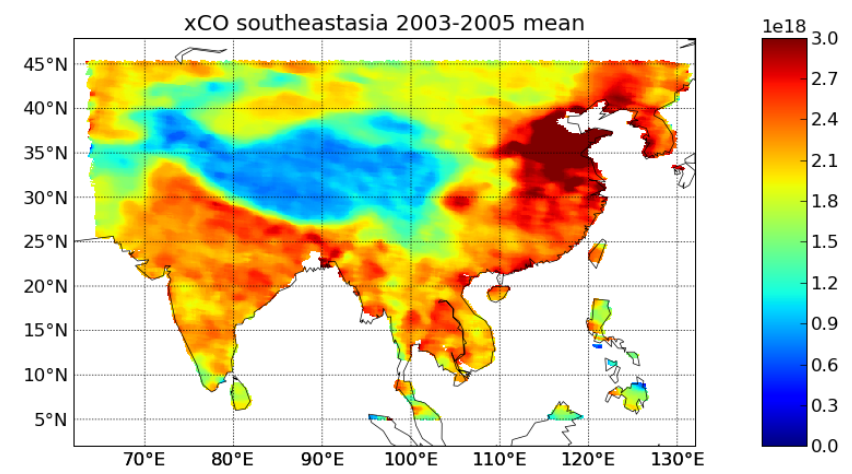

Fig. 19. Three-year average of $\mathrm{CO}$ vertical column densities $\left[\right.$ molec cm ${ }^{-2}$ ] over South-East Asia. $\left(0.2^{\circ} \times 0.2^{\circ}\right.$ grid with $1^{\circ} \times 1^{\circ}$ median filter smoothing).
Dils et al. (2006) described comparisons between SCIAMACHY CO, $\mathrm{CH}_{4}, \mathrm{CO}_{2}$, and $\mathrm{N}_{2} \mathrm{O}$ total columns retrieved by three different algorithms (WFM-DOAS, Buchwitz et al., 2004; IMAP-DOAS, Frankenberg et al., 2005a; and IMLM, de Laat et al., 2006) and ground-based FTIR data measured at eleven NDACC (then NDSC) stations. More recently, de Laat et al. (2010) reported good agreement between SCIAMACHY IMLM retrievals of carbon monoxide with twenty ground-based stations (mostly FTIR).

These intercomparisons are delicate since the instruments have different altitude sensitivity and horizontal resolution, the temporal match of the observations is not ideal and the location of the ground stations and the surrounding terrain may also be an impediment. Nevertheless, these studies allow an assessment of, e.g. relative biases or inter-annual variability and are an important element of the validation efforts.

Satellites observe large areas in contrast to the point-like view of uplooking ground-based spectrometers, so they see 
in general a larger portion of the atmosphere. If comparisons were performed over a largely uniform surface terrain without emission sources, the problem of the horizontal resolution would be reduced. Accordingly, oceans are natural candidates but, in the absence of clouds, the signal received is rather weak because of the low albedo of water (see also Gloudemans et al., 2009). Another possibility is to use desert areas without significant emissions. Although deserts can exhibit altitude differences, they typically have high surface albedos providing high signal-to-noise ratios.

Here, SCIAMACHY CO BIRRA retrievals are compared to the ground-based measurements provided by the World Data Center for Greenhouse Gases (WDCGG) Assekrem Station (Novelli et al., 2003). It is important to note at this point that the SCIAMACHY CO retrievals represent (dryair) column mixing ratios (i.e. considering the a-priori column mixing ratio $q_{\mathrm{CO}}^{\text {prior }}$ instead of the a-priori vertical column density $N_{\mathrm{CO}}^{\text {prior }}$ in Eq. (19)), whereas the Assekrem station measured volume mixing ratios at surface level. Such a comparison is only justified for gases with constant mixing ratio profiles (e.g. $\mathrm{O}_{2}, \mathrm{CO}_{2}$ ) and this is not the case of $\mathrm{CO}$. This study in not intended to be a validation, since we are comparing two different quantities. However, both retrievals should show similar seasonality features and temporal evolution (and indeed they do) and this is our motivation here.

Figure 20 illustrates time series of 14-day averaged dry-air CO column mixing ratios as observed by SCIAMACHY and $\mathrm{CO}$ volume mixing ratios as measured at the Assekrem WDCGG ground station. In the Northern Hemisphere, higher column densities can be expected in winter, and this can be clearly seen in Fig. 20. Furthermore, the seasonal variation of carbon monoxide retrieved with BIRRA is also evident in the ground-based measurements. A good agreement of SCIAMACHY's and the Assekrem ground station $\mathrm{CO}$ is found for the years of 2003, 2004 and 2005. Afterward, due to instrument degradation, the SCIAMACHY CO shows a higher dispersion and the seasonal variation is worse represented (esp. in 2006).

\subsection{Methane}

Methane is the third (second anthropogenic) most important greenhouse gas representing one fifth of the whole radiative forcing of long-life well-mixed gases. Its concentration has increased by more than a factor of two since pre-industrial times with a growth rate of about $1 \%$ per annum (until recently). Atmospheric methane results from anthropogenic (agriculture, fossil fuel combustion, ...) as well as natural (e.g. wetlands, geological processes) sources. With a life time of about ten years, its spatial and temporal variation is considerably smaller than for $\mathrm{CO}$. As a consequence, the required retrieval precision is much higher.

Atmospheric sounding of methane is performed in the near and thermal infrared, and it is observed by all sensors mentioned above (e.g. Buchwitz et al., 2005; Frankenberg

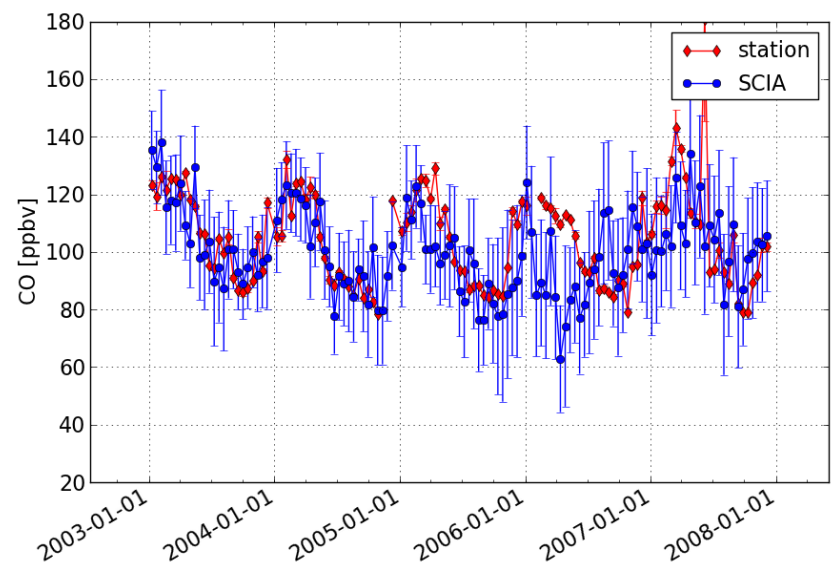

Fig. 20. Intercomparison of SCIAMACHY CO over Central Sahara with Assekrem WDCGG station (Ahaggar Mountains, $2710 \mathrm{~m}$ above sea level) data. Note that the SCIAMACHY CO retrievals are dry-air column mixing ratios and the Assekrem WDCGG CO data are volume mixing ratios at surface level. The time step is in both cases 14 days. The error bars represent the standard deviation of the data.

et al., 2006; Gloudemans et al., 2008). Furthermore, it is one of the two target gases of the TANSO Fourier transform spectrometer on-board the recently launched GOSAT satellite (Kuze et al., 2009).

For methane retrievals from SCIAMACHY observations, two microwindows in channel 6 are utilized: the $5986-6139 \mathrm{~cm}^{-1}$ interval with $\mathrm{CH}_{4}$ as the strongest absorber, and the $6273-6419 \mathrm{~cm}^{-1}$ interval with $\mathrm{CO}_{2}$ as the strongest absorber. For our retrievals, $\mathrm{H}_{2} \mathrm{O}$ has been considered as additional absorber in both windows, the Gaussian slit function HWHM has been fixed to 2.45 and $2.64 \mathrm{~cm}^{-1}$ in the two windows, and albedo was modeled as a second degree polynomial.

Figure 21 gives an impression of three month averages for 2004. Regions of strong emissions, e.g. the northern South America, the equatorial region of Africa, and in Asia are clearly visible and reflect patterns found by, e.g. Frankenberg et al. (2006); Schneising et al. (2009). Seasonal variability such as increased emissions in South East Asia due to rice cultivation is evident especially for July-August-September. Furthermore, the plot shows the shift of methane emissions over wetlands from southern to northern Africa and back.

\section{Summary and outlook}

A new code BIRRA - Beer InfraRed Retrieval Algorithm has been developed for level $1 \mathrm{~b} \rightarrow 2$ processing of SCIAMACHY near infrared nadir observations. Recently, the BIRRA code has been successfully implemented into the operational SCIAMACHY processor for the retrieval of carbon monoxide vertical column densities. In view of its efficiency, 

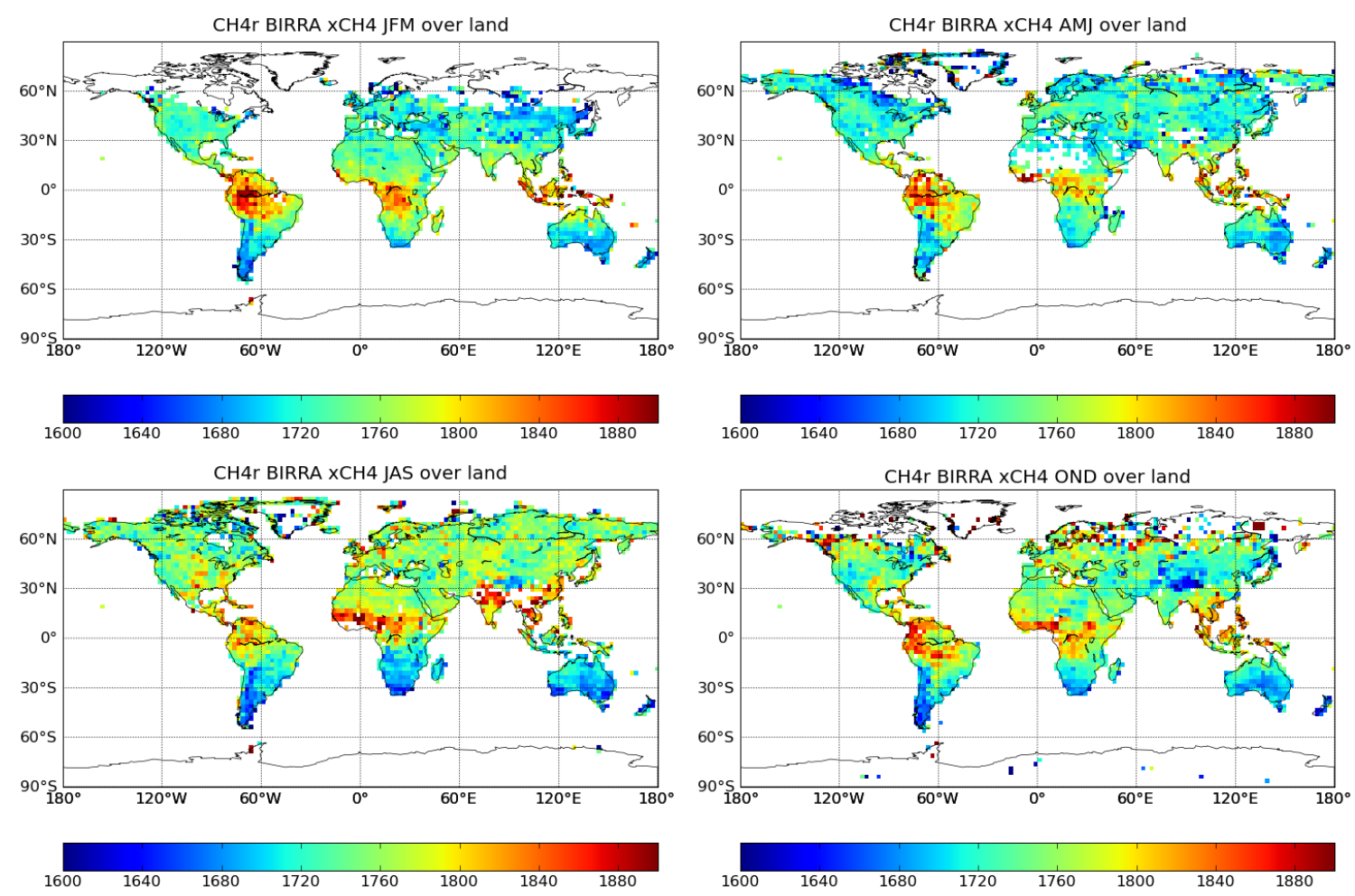

Fig. 21. Quarterly means of methane [ppm] for 2004. In view of the reduced signal over oceans, only $\mathrm{CH}_{4}$ over land is plotted. $\left(2^{\circ} \times 2^{\circ}\right.$ grid)

flexibility and precision, BIRRA is also a suitable tool for scientific investigations.

The fundamentals of the algorithm have been presented in Sect. 2. BIRRA analyzes radiance spectra instead of optical thicknesses (as in DOAS-like algorithms), since instruments measure the convolved radiance rather than the convolved optical thickness.

The inversion is done by standard nonlinear least squares or by separable least squares solvers, where linear and nonlinear parameters are treated separately. Further distinctive features of the code are the optional use of bound constrained least squares, exact analytical derivatives by automatic differentiation, and "on demand" line-by-line computation of molecular cross sections.

The results presented here are dry-air quantities: vertical column densities in case of $\mathrm{CO}$, with $\mathrm{CH}_{4}$ as proxy; and dry-air column mixing ratios in case of $\mathrm{CH}_{4}$, with $\mathrm{CO}_{2}$ as proxy. Whereas $\mathrm{CO}_{2}$ is a good proxy for the dry air mass of the observations, $\mathrm{CH}_{4}$ has some deficiencies (much stronger spectral signatures than $\mathrm{CO}$, spatial variability, non-constant profile, etc). However, due to the much greater variability of $\mathrm{CO}, \mathrm{CH}_{4}$ can be used as an appropriate proxy.

Several aspects of the level 1 data have been investigated. It turned out that the effect of the dead/bad pixel mask (DBPM) has a major impact on the retrievals. In addition to masking spectral pixels with doubtful level 1 quality, one has to consider further masking due to spectroscopic aspects; in particular, interference of spectral lines of the target gas with strong lines of other gases, or insufficient knowledge of the molecular cross sections due to imprecise spectral line parameters. The use of radiance spectra normalized by sun mean reference (SMR) spectra helps reducing the impact of the ice layer over the detector on the retrievals. However, in case of BIRRA, the ice layer affects $\mathrm{CO}$ and $\mathrm{CH}_{4}$ differently and further treatment is needed. The pixel-to-wavelength relationship of channel 8 in SCIAMACHY level-1b product is set to the on-ground calibration and a spectral correction is needed. We found that the required spectral correction has roughly a second-degree polynomial shape that can be well approximated by a first-degree polynomial in the $\mathrm{CO}$ fitting window.

A survey of carbon monoxide and methane VCD retrievals has been presented with emphasis on the years 2003 to 2005 . "Pre-" and "postprocessing" of the data turned out to be crucial, i.e. careful preparation of the level $1 \mathrm{~b}$ data used as input to the least squares fitting and a meticulous examination of the fitted column density scaling factors for the generation of scientific products is mandatory. In addition, the final product is highly sensitive to the correct filtering of dubious retrievals and to the appropriate consideration of scene cloudiness. Moreover, careful analysis of the time series of all fit parameters with respect to the instrumental mean 
transmittance provides valuable hints for the postprocessing. Preliminary work exploiting SCIAMACHY's channel 6 shows BIRRA's potential for methane (and carbon dioxide) retrievals.

The further development of BIRRA is motivated by its dual role as an operational processor and a scientific tool. For the "scientific prototype", we are currently working on an optimization and fine-tuning of the multiwindow fitting (required for methane and carbon dioxide retrievals). Furthermore, a better climatology esp. of temperature and water would be beneficial and likewise the treatment of clouds and aerosols can be improved in the forward model and/or in the post-processing. Finally, our verification and validation efforts will be intensified, e.g. by intercomparisons with ground-based observations (NDACC-TCCON) as well as thermal infrared sounders such as AIRS, GOSAT, IASI, MOPITT, and TES (Schreier et al., 2010). Clearly, the lessons learned from the scientific analysis will be a valuable guide for the ongoing upgrade of the operational processor. The further refinement will allow a better analysis of the years 2006 and beyond that are even more challenging due to the continuous channel degradation, nb. increasing number of bad or dead pixels.

Acknowledgements. Numerous discussions in the SADDU working group (esp. with Michael Buchwitz and Heinrich Bovensmann, University Bremen; and Annemieke Gloudemans, Hans Schrijver, and Christian Frankenberg, SRON) are gratefully acknowledged. In particular we thank Michael Buchwitz for providing SCIAMACHY level 1, the channel 8 DBPM, and level 2 (WFM-DOAS) data, http://www.iup.uni-bremen.de/sciamachy/ NIR_NADIR_WFM_DOAS/; Annemieke Gloudemans and Hans Schrijver kindly provided their SCIAMACHY carbon monoxide total column data. Data of ground-based CO measurements were downloaded from the World Data Centre for Greenhouse Gases (WDCGG) at http://gaw.kishou.go.jp/wdcgg/wdegg.html. Finally we would like to thank our colleagues Adrian Doicu, Michael Hess, Thomas Trautmann, and Mayte Vasquez for stimulating discussions and Bernd Aberle, Klaus Kretschel, and Markus Meringer for computational support.

Edited by: P. K. Bhartia

\section{References}

Abrams, M. C., Goldman, A., Gunson, M. R., Rinsland, C. P., and Zander, R.: Observations of the Infrared Solar Spectrum from Space by the ATMOS experiment, Appl. Opt., 35, 2747-2751, doi:10.1364/AO.35.002747, 1996.

Anderson, G. P., Clough, S. A., Kneizys, F. X., Chetwynd, J. H., and Shettle, E. P.: AFGL Atmospheric Constituent Profiles (0120km), Tech. Rep. TR-86-0110, AFGL, 1986.

Berk, A., Anderson, G. P., Acharya, P. K., Bernstein, L. S., Chetwynd, J. H., Matthew, M. W., Shettle, E. P., and AdlerGolden, S. M.: MODTRAN4 User's Manual, Tech. rep., Air Force Research Laboratory, Mass., USA, 1999.
Bovensmann, H., Burrows, J. P., Buchwitz, M., Frerick, J., Noël, S., Rozanov, V. V., Chance, K. V., and Goede, A. P. H.: SCIAMACHY: Mission Objectives and Measurement Mode, J. Atmos. Sci., 56, 127-150, doi:10.1175/15200469(1999)056;0127:SMOAMM ;2.0.CO;2, 1999.

Buchwitz, M., Rozanov, V. V., and Burrows, J. P.: A near-infrared optimized DOAS method for the fast global retrieval of atmospheric $\mathrm{CH}_{4}, \mathrm{CO}, \mathrm{CO}_{2}, \mathrm{H}_{2} \mathrm{O}$, and $\mathrm{N}_{2} \mathrm{O}$ total column amounts from SCIAMACHY Envisat-1 nadir radiances, J. Geophys. Res., 105, 15231-15245, doi:10.1029/2000JD900191, 2000.

Buchwitz, M., de Beek, R., Bramstedt, K., Noël, S., Bovensmann, H., and Burrows, J. P.: Global carbon monoxide as retrieved from SCIAMACHY by WFM-DOAS, Atmos. Chem. Phys., 4, 19451960, doi:10.5194/acp-4-1945-2004, 2004.

Buchwitz, M., de Beek, R., Noël, S., Burrows, J. P., Bovensmann, H., Bremer, H., Bergamaschi, P., Körner, S., and Heimann, M.: Carbon monoxide, methane and carbon dioxide columns retrieved from SCIAMACHY by WFM-DOAS: year 2003 initial data set, Atmos. Chem. Phys., 5, 3313-3329, doi:10.5194/acp-53313-2005, 2005.

Buchwitz, M., de Beek, R., Noël, S., Burrows, J. P., Bovensmann, H., Schneising, O., Khlystova, I., Bruns, M., Bremer, H., Bergamaschi, P., Körner, S., and Heimann, M.: Atmospheric carbon gases retrieved from SCIAMACHY by WFM-DOAS: version $0.5 \mathrm{CO}$ and $\mathrm{CH}_{4}$ and impact of calibration improvements on $\mathrm{CO}_{2}$ retrieval, Atmos. Chem. Phys., 6, 2727-2751, doi:10.5194/acp6-2727-2006, 2006.

Buchwitz, M., Khlystova, I., Bovensmann, H., and Burrows, J. P.: Three years of global carbon monoxide from SCIAMACHY: comparison with MOPITT and first results related to the detection of enhanced CO over cities, Atmos. Chem. Phys., 7, 23992411, doi:10.5194/acp-7-2399-2007, 2007.

Clerbaux, C., Edwards, D. P., Deeter, M., Emmons, L., Lamarque, J.-F., Tie, X. X., Massie, S. T., and Gille, J.: Carbon monoxide pollution from cities and urban areas observed by the Terra/MOPITT mission, Geophys. Res. Letters, 35, L03817, doi:10.1029/2007GL032300, 2008.

Clough, S. A., Kneizys, F. X., and Davies, R.: Line Shape and the Water Vapor Continuum, Atmos. Res., 23, 229-241, doi:10.1016/0169-8095(89)90020-3, 1989.

de Laat, A., Gloudemans, A., Schrijver, H., van den Broek, M., Meirink, J., Aben, I., and Krol, M.: Quantitative analysis of SCIAMACHY carbon monoxide total column measurements, Geophys. Res. Lett., 33, L07807, doi:10.1029/2005GL025530, 2006.

de Laat, A. T. J., Gloudemans, A. M. S., Aben, I., Krol, M., Meirink, J. F., van der Werf, G. R., and Schrijver, H.: Scanning Imaging Absorption Spectrometer for Atmospheric Chartography carbon monoxide total columns: Statistical evaluation and comparison with chemistry transport model results, J. Geophys. Res., 112, D12310, doi:10.1029/2006JD008256, 2007.

de Laat, A. T. J., Gloudemans, A. M. S., Schrijver, H., Aben, I., Nagahama, Y., Suzuki, K., Mahieu, E., Jones, N. B., Paton-Walsh, C., Deutscher, N. M., Griffith, D. W. T., De Mazière, M., Mittermeier, R. L., Fast, H., Notholt, J., Palm, M., Hawat, T., Blumenstock, T., Hase, F., Schneider, M., Rinsland, C., Dzhola, A. V., Grechko, E. I., Poberovskii, A. M., Makarova, M. V., Mellqvist, J., Strandberg, A., Sussmann, R., Borsdorff, T., and Rettinger, M.: Validation of five years $(2003-2007)$ of SCIAMACHY CO 
total column measurements using ground-based spectrometer observations, Atmos. Meas. Tech., 3, 1457-1471, doi:10.5194/amt3-1457-2010, 2010.

Deeter, M. N., Edwards, D. P., Gille, J. C., and Drummond, J. R.: $\mathrm{CO}$ retrievals based on MOPITT near-infrared observations, J. Geophys. Res., 114, D04303, doi:10.1029/2008JD010872, 2009.

Deeter, M. N., Emmons, L. K., Francis, G. L., Edwards, D. P., Gille, J. C., Warner, J. X., Khattatov, B., Ziskin, D., Lamarque, J.-F., Ho, S.-P., Yudin, V., Attié, J.-L., Packman, D., Chen, J., Mao, D., and Drummond, J. R.: Operational carbon monoxide retrieval algorithm and selected results for the MOPITT instrument, J. Geophys. Res., 108, 4399, doi:10.1029/2002JD003186, 2003.

Dennis, Jr., J. E., Gay, D. M., and Welsch, R. E.: An Adaptive Nonlinear Least-Squares Algorithm, ACM Trans. Math. Soft., 7, 348-368, doi:10.1145/355958.355965, 1981.

Dils, B., De Mazière, M., Müller, J. F., Blumenstock, T., Buchwitz, M., de Beek, R., Demoulin, P., Duchatelet, P., Fast, H., Frankenberg, C., Gloudemans, A., Griffith, D., Jones, N., Kerzenmacher, T., Kramer, I., Mahieu, E., Mellqvist, J., Mittermeier, R. L., Notholt, J., Rinsland, C. P., Schrijver, H., Smale, D., Strandberg, A., Straume, A. G., Stremme, W., Strong, K., Sussmann, R., Taylor, J., van den Broek, M., Velazco, V., Wagner, T., Warneke, T., Wiacek, A., and Wood, S.: Comparisons between SCIAMACHY and ground-based FTIR data for total columns of $\mathrm{CO}, \mathrm{CH}_{4}, \mathrm{CO}_{2}$ and $\mathrm{N}_{2} \mathrm{O}$, Atmos. Chem. Phys., 6, 1953-1976, doi:10.5194/acp6-1953-2006, 2006.

ETOPO4: 2-minute Gridded Global Relief Data (ETOPO2v2), Tech. Rep., US Department of Commerce, National Oceanic and Atmospheric Administration, National Geophysical Data Center, available at: http://www.ngdc.noaa.gov/mgg/, 2006.

Feng, X. and Zhao, F.-S.: Effect of changes of the HITRAN database on transmittance calculations in the near-infrared region, J. Quant. Spectrosc. \& Radiat. Transfer, 110, 247-255, doi:10.1016/j.jqsrt.2008.10.004, 2009.

Fleming, E. L., Chandra, S., Barnett, J. J., and Corney, M.: Zonal mean temperature, pressure, zonal wind and geopotential height as functions of latitude, Adv. Space Res., 10, 11-59, doi:10.1016/0273-1177(90)90386-E, 1990.

Fortems-Cheiney, A., Chevallier, F., Pison, I., Bousquet, P., Carouge, C., Clerbaux, C., Coheur, P.-F., George, M., Hurtmans, D., and Szopa, S.: On the capability of IASI measurements to inform about CO surface emissions, Atmos. Chem. Phys., 9, 87358743, doi:10.5194/acp-9-8735-2009, 2009.

Frankenberg, C., Platt, U., and Wagner, T.: Retrieval of CO from SCIAMACHY onboard ENVISAT: detection of strongly polluted areas and seasonal patterns in global CO abundances, Atmos. Chem. Phys., 5, 1639-1644, doi:10.5194/acp-5-1639-2005, 2005a.

Frankenberg, C., Platt, U., and Wagner, T.: Iterative maximum a posteriori (IMAP)-DOAS for retrieval of strongly absorbing trace gases: Model studies for $\mathrm{CH}_{4}$ and $\mathrm{CO}_{2}$ retrieval from near infrared spectra of SCIAMACHY onboard ENVISAT, Atmos. Chem. Phys., 5, 9-22, doi:10.5194/acp-5-9-2005, 2005b.

Frankenberg, C., Meirink, J. F., Bergamaschi, P., Goede, A. P. H., Heimann, M., Körner, S., Platt, U., van Weele, M., and Wagner, T.: Satellite chartography of atmospheric methane from SCIAMACHY on board ENVISAT: Analysis of the years 2003 and 2004, J. Geophys. Res., 111, D07303, doi:10.1029/2005JD006235, 2006.
Frankenberg, C., Bergamaschi, P., Butz, A., Houweling, S., Meirink, J. F., Notholt, J., Petersen, A. K., Schrijver, H., Warneke, T., and Aben, I.: Tropical methane emissions: A revised view from SCIAMACHY onboard ENVISAT, Geophys. Res. Lett., 35, L15811, doi:10.1029/2008GL034300, 2008a.

Frankenberg, C., Warneke, T., Butz, A., Aben, I., Hase, F., Spietz, P., and Brown, L. R.: Pressure broadening in the $2 v_{3}$ band of methane and its implication on atmospheric retrievals, Atmos. Chem. Phys., 8, 5061-5075, doi:10.5194/acp-8-5061-2008, 2008b.

Gay, D. M.: Usage Summary for Selected Optimization Routines (PORT Mathematical Subroutine Library, Optimization chapter), Computing Science Technical Report 153, AT\&T Bell Laboratories, Murray Hill, NJ 07974, available at http://netlib.bell-labs. com/cm/cs/cstr/153.pdf, 1990.

George, M., Clerbaux, C., Hurtmans, D., Turquety, S., Coheur, P.F., Pommier, M., Hadji-Lazaro, J., Edwards, D. P., Worden, H., Luo, M., Rinsland, C., and McMillan, W.: Carbon monoxide distributions from the IASI/METOP mission: evaluation with other space-borne remote sensors, Atmos. Chem. Phys., 9, 8317-8330, doi:10.5194/acp-9-8317-2009, 2009.

Gloudemans, A. M. S., Schrijver, H., Kleipool, Q., van den Broek, M. M. P., Straume, A. G., Lichtenberg, G., van Hees, R. M., Aben, I., and Meirink, J. F.: The impact of SCIAMACHY nearinfrared instrument calibration on $\mathrm{CH}_{4}$ and $\mathrm{CO}$ total columns, Atmos. Chem. Phys., 5, 2369-2383, doi:10.5194/acp-5-23692005, 2005.

Gloudemans, A. M. S., Krol, M. C., Meirink, J. F., de Laat, A. T. J., van der Werf, G. R., Schrijver, H., van den Broek, M. M. P., and Aben, I.: Evidence for long-range transport of carbon monoxide in the Southern Hemisphere from SCIAMACHY observations, Geophys. Res. Lett., 33, L16807, doi:10.1029/2006GL026804, 2006.

Gloudemans, A. M. S., Schrijver, H., Hasekamp, O. P., and Aben, I.: Error analysis for $\mathrm{CO}$ and $\mathrm{CH}_{4}$ total column retrievals from SCIAMACHY $2.3 \mu \mathrm{m}$ spectra, Atmos. Chem. Phys., 8, 39994017, doi:10.5194/acp-8-3999-2008, 2008.

Gloudemans, A. M. S., de Laat, A. T. J., Schrijver, H., Aben, I., Meirink, J. F., and van der Werf, G. R.: SCIAMACHY CO over land and oceans: 2003-2007 interannual variability, Atmos. Chem. Phys., 9, 3799-3813, doi:10.5194/acp-9-3799-2009, 2009.

Golub, G. and Pereyra, V.: Separable nonlinear least squares: the variable projection method and its applications, Inverse Problems, 19, R1-R26, doi:10.1088/0266-5611/19/2/201, 2003.

Gottwald, M. and Bovensmann, H. (Eds.): SCIAMACHY - Exploring the Changing Earth's Atmosphere, Springer, doi:10.1007/978-90-481-9896-2, 2011.

Griewank, A.: Evaluating Derivatives: Principles and Techniques of Algorithmic Differentiation, SIAM, Philadelphia, PA, 2000.

Hascoët, L. and Pascual, V.: TAPENADE 2.1 user's guide, Technical Report 0300, INRIA, http://www.inria.fr/rrrt/rt-0300.html, 2004.

Hase, F., Demoulin, P., Sauval, A. J., Toon, G. C., Bernath, P. F., Goldman, A., Hannigan, J. W., and Rinsland, C. P.: An empirical line-by-line model for the infrared solar transmittance spectrum from 700 to $5000 \mathrm{~cm}^{-1}$, J. Quant. Spectrosc. \& Radiat. Transfer, 102, 450-463, doi:10.1016/j.jqsrt.2006.02.026, 2006.

Hedelt, P., Alonso, R., Brown, T., Collados Vera, M., Rauer, H., 
Schleicher, H., Schmidt, W., Schreier, F., and Titz, R.: Venus transit 2004: Illustrating the capability of exoplanet transmission spectroscopy, Astron. Astrophys., 533, A136, doi:10.1051/00046361/201016237, 2011.

Illingworth, S. M., Remedios, J. J., Boesch, H., Moore, D. P., Sembhi, H., Dudhia, A., and Walker, J. C.: ULIRS, an optimal estimation retrieval scheme for carbon monoxide using IASI spectral radiances: sensitivity analysis, error budget and simulations, Atmos. Meas. Tech., 4, 269-288, doi:10.5194/amt-4-269-2011, 2011.

Jacquinet-Husson, N., Scott, N. A., Chedin, A., Crepeau, L., Armante, R., Capelle, V., Orphal, J., Coustenis, A., Boonne, C., Poulet-Crovisier, N., Barbe, A., Birk, M., Brown, L. R., CamyPeyret, C., Claveau, C., Chance, K., Christidis, N., Clerbaux, C., Coheur, P. F., Dana, V., Daumont, L., Backer-Barilly, M. R. D., Lonardo, G. D., Flaud, J. M., Goldman, A., Hamdouni, A., Hess, M., Hurley, M. D., Jacquemart, D., Kleiner, I., Köpke, P., Mandin, J. Y., Massie, S., Mikhailenko, S., Nemtchinov, V., Nikitin, A., Newnham, D., Perrin, A., Perevalov, V. I., Pinnock, S., Regalia-Jarlot, L., Rinsland, C. P., Rublev, A., Schreier, F., Schult, L., Smith, K. M., Tashkun, S. A., Teffo, J. L., Toth, R. A., Tyuterev, V., Auwera, J. V., Varanasi, P., and Wagner, G.: The GEISA spectroscopic database: Current and future archive for Earth and planetary atmosphere studies, J. Quant. Spectrosc. \& Radiat. Transfer, 109, 1043-1059, doi:10.1016/j.jqsrt.2007.12.015, 2008.

Kurucz, R. L.: The Solar Irradiance by Computation, in: Proceedings of the 17th Annual Review Conference on Atmospheric Transmission Models, edited by Anderson, G. P., Picard, R. H., and Chetwynd, J. H., PL/TR-95-2060, 274, Phillips Laboratory/Geophysics Directorate, 1995.

Kuze, A., Suto, H., Nakajima, M., and Hamazaki, T.: Thermal and near infrared sensor for carbon observation Fouriertransform spectrometer on the Greenhouse Gases Observing Satellite for greenhouse gases monitoring, Appl. Opt., 48, 67166733, doi:10.1364/AO.48.006716, 2009.

Lerot, C., van Roozendael, M., Lambert, J.-C., Granville, J., van Gent, J., Loyola, D., and Spurr, R.: The GODFIT algorithm: a direct fitting approach to improve the accuracy of total ozone measurements from GOME, Int. J. Remote Sens., 31, 543-550, doi:10.1080/01431160902893576, 2010.

Lichtenberg, G., Kleipool, Q., Krijger, J. M., van Soest, G., van Hees, R., Tilstra, L. G., Acarreta, J. R., Aben, I., Ahlers, B., Bovensmann, H., Chance, K., Gloudemans, A. M. S., Hoogeveen, R. W. M., Jongma, R. T. N., Noël, S., Piters, A., Schrijver, H., Schrijvers, C., Sioris, C. E., Skupin, J., Slijkhuis, S., Stammes, P., and Wuttke, M.: SCIAMACHY Level 1 data: calibration concept and in-flight calibration, Atmos. Chem. Phys., 5, 5347-5367, doi:10.5194/acp-6-5347-2006, 2006.

Lichtenberg, G., Gimeno García, S., Schreier, F., Slijkhuis, S., Snel, R., and Bovensmann, H.: Impact of Level 1 Quality on SCIAMACHY Level 2 Retrieval, in: 38. COSPAR Scientific Assembly, 2010.

Liou, K.-N.: An Introduction to Atmospheric Radiation, Academic Press, Orlando, 1980.

McMillan, W. W., Barnet, C., Strow, L., Chahine, M. T., McCourt, M. L., Warner, J. X., Novelli, P. C., Korontzi, S., Maddy, E. S., and Datta, S.: Daily global maps of carbon monoxide from NASA's Atmospheric Infrared Sounder, Geophys. Res. Lett., 32,
L11801, doi:10.1029/2004GL021821, 2005.

McMillan, W. W., Warner, J. X., McCourt Comer, M., Maddy, E., Chu, A., Sparling, L., Eloranta, E., Hoff, R., Sachse, G., Barnet, C., Razenkov, I., and Wolf, W.: AIRS views transport from 12 to 22 July 2004 Alaskan/Canadian fires: Correlation of AIRS CO and MODIS AOD with forward trajectories and comparison of AIRS CO retrievals with DC-8 in situ measurements during INTEX-A/ICARTT, J. Geophys. Res., 113, D20301, doi:10.1029/2007JD009711, 2008.

Melsheimer, C., Verdes, C., Buehler, S. A., Emde, C., Eriksson, P., Feist, D. G., Ichizawa, S., John, V. O., Kasai, Y., Kopp, G., Koulev, N., Kuhn, T., Lemke, O., Ochiai, S., Schreier, F., Sreerekha, T. R., Suzuki, M., Takahashi, C., Tsujimaru, S., and Urban, J.: Intercomparison of General Purpose Clear Sky Atmospheric Radiative Transfer Models for the Millimeter/Submillimeter Spectral Range, Radio Sci., 40, RS1007, doi:10.1029/2004RS003110, 2005.

Mendrok, J., Schreier, F., and Höpfner, M.: Estimating cirrus cloud properties from MIPAS data, Geophys. Res. Lett., 34, L08807, doi:10.1029/2006GL028246, 2007.

Novelli, P. C., Masarie, K. A., Lang, P. M., Hall, B. D., Myers, R. C., and Elkins, J. W.: Reanalysis of tropospheric CO trends: Effects of the 1997-1998 wildfires, J. Geophys. Res., 108, D04464, doi:10.1029/2002JD003031, 2003.

Reuter, M., Buchwitz, M., Schneising, O., Heymann, J., Bovensmann, H., and Burrows, J. P.: A method for improved SCIAMACHY $\mathrm{CO}_{2}$ retrieval in the presence of optically thin clouds, Atmos. Meas. Tech., 3, 209-232, doi:10.5194/amt-3-209-2010, 2010.

Rinsland, C. P., Luo, M., Logan, J. A., Beer, R., Worden, H. M., Worden, J. R., Bowman, K., Kulawik, S. S., Rider, D., Osterman, G., Gunson, M., Goldman, A., Shephard, M., Clough, S. A., Rodgers, C., Lampel, M., and Chiou, L.: Nadir Measurements of Carbon Monoxide Distributions by the Tropospheric Emission Spectrometer onboard the Aura Spacecraft: Overview of Analysis Approach and Examples of Initial Results, Geophys. Res. Lett., 33, L22806, doi:10.1029/2006GL027000, 2006.

Rothman, L. S., Gordon, I. E., Barbe, A., Benner, D. C., Bernath, P. F., Birk, M., Boudon, V., Brown, L. R., Campargue, A., Champion, J.-P., Chance, K., Coudert, L. H., Dana, V., Devi, V. M., Fally, S., Flaud, J.-M., Gamache, R. R., Goldman, A., Jacquemart, D., Kleiner, I., Lacome, N., Lafferty, W. J., Mandin, J.-Y., Massie, S. T., Mikhailenko, S. N., Miller, C. E., Moazzen-Ahmadi, N., Naumenko, O. V., Nikitin, A. V., Orphal, J., Perevalov, V. I., Perrin, A., Predoi-Cross, A., Rinsland, C. P., Rotger, M., Simecková, M., Smith, M. A. H., Sung, K., Tashkun, S. A., Tennyson, J., Toth, R. A., Vandaele, A. C., and Auwera, J. V.: The HITRAN 2008 molecular spectroscopic database, J. Quant. Spectrosc. \& Radiat. Transfer, 110, 533-572, doi:10.1016/j.jqsrt.2009.02.013, 2009.

Schneising, O., Buchwitz, M., Burrows, J. P., Bovensmann, H., Bergamaschi, P., and Peters, W.: Three years of greenhouse gas column-averaged dry air mole fractions retrieved from satellite - Part 2: Methane, Atmos. Chem. Phys., 9, 443-465, doi:10.5194/acp-9-443-2009, 2009.

Schreier, F.: Optimized Implementations of Rational Approximations for the Voigt and Complex Error Function, J. Quant. Spectrosc. \& Radiat. Transfer, 112, 1010-1025, doi:10.1016/j.jqsrt.2010.12.010, 2011. 
Schreier, F. and Schimpf, B.: A New Efficient Line-By-Line Code for High Resolution Atmospheric Radiation Computations incl. Derivatives, in: IRS 2000: Current Problems in Atmospheric Radiation, edited by Smith, W. L. and Timofeyev, Y., pp. 381-384, A. Deepak Publishing, 2001.

Schreier, F., Gimeno García, S., Hess, M., Doicu, A., von Bargen, A., Buchwitz, M., Khlystova, I., Bovensmann, H., and Burrows, J. P.: Intercomparison of vertical column densities derived from SCIAMACHY infrared nadir observations, in: Proceedings of Envisat Symposium 2007, edited by Lacoste, H. and Ouwehand, L., vol. SP-636, ESA, 2007.

Schreier, F., Gimeno García, S., Lichtenberg, G., and Hess, M.: Intercomparison of Near Infrared SCIAMACHY and Thermal Infrared Nadir Vertical Column Densities, in: Proceedings of ESA Living Planet Symposium, edited by Lacoste-Francis, H., vol. SP-686, ESA, 2010.

Sussmann, R. and Buchwitz, M.: Initial validation of ENVISAT/SCIAMACHY columnar CO by FTIR profile retrievals at the Ground-Truthing Station Zugspitze, Atmos. Chem. Phys., 5, 1497-1503, doi:10.5194/acp-5-1497-2005, 2005.

Tran, H., Hartmann, J.-M., Toon, G., Brown, L. R., Frankenberg, C., Warneke, T., Spietz, P., and Hase, F.: The $2 v_{3}$ band of $\mathrm{CH}_{4}$ revisited with line mixing: Consequences for spectroscopy and atmospheric retrievals at $1.67 \mu \mathrm{m}$, J. Quant. Spectrosc. \& Radiat. Transfer, 111, 1344-1356, doi:10.1016/j.jqsrt.2010.02.015, 2010 . von Clarmann, T., Höpfner, M., Funke, B., López-Puertas, M., Dudhia, A., Jay, V., Schreier, F., Ridolfi, M., Ceccherini, S., Kerridge, B. J., Reburn, J., and Siddans, R.: Modeling of Atmospheric Mid-Infrared Radiative Transfer: The AMIL2DA Algorithm Intercomparison Experiment, J. Quant. Spectrosc. \& Radiat. Transfer, 78, 381-407, doi:10.1016/S0022-4073(02)00262-5, 2002.

Wallace, L. and Livingston, W.: Spectroscopic Observations of Atmospheric Trace Gases over Kitt Peak 1. Carbon Dioxide and Methane from 1979 to 1985, J. Geophys. Res., 95, 9823-9827, doi:10.1029/JD095iD07p09823, 1990.

Worden, H. M., Deeter, M. N., Edwards, D. P., Gille, J. C., Drummond, J. R., and Nédélec, P.: Observations of near-surface carbon monoxide from space using MOPITT multispectral retrievals, J. Geophys. Res., 115, D16314, doi:10.1029/2010JD014242, 2010.

Yang, Z., Toon, G. C., Margolis, J. S., and Wennberg, P. O.: Atmospheric $\mathrm{CO}_{2}$ retrieved from ground-based solar spectra, Geophys. Res. Letters, 29, 1339, doi:10.1029/2001GL014537, 2002

Yurganov, L. N., McMillan, W. W., Dzhola, A. V., Grechko, E. I., Jones, N. B., and van der Werf, G. R.: Global AIRS and MOPITT CO measurements: Validation, comparison, and links to biomass burning variations and carbon cycle, J. Geophys. Res., 113, D09301, doi:10.1029/2007JD009229, 2008.

Zdunkowski, W., Trautmann, T., and Bott, A.: Radiation in the Atmosphere - A Course in Theoretical Meteorology, Cambridge University Press, 2007. 